\title{
Boundary Layer Quasi-Equilibrium Limits Convective Intensity Enhancement from the Diurnal Cycle in Surface Heating
}

\author{
Zachary R. Hansen, ${ }^{\text {a }}$ Larissa E. BACK, And Peigen Zhou \\ University of Wisconsin-Madison, Madison, Wisconsin
}

(Manuscript received 28 November 2018, in final form 8 October 2019)

\begin{abstract}
A combination of cloud-permitting model (CPM) simulations, satellite, and reanalysis data are used to test whether the diurnal cycle in surface temperature has a significant impact on the intensity of deep convection as measured by high-percentile updraft velocities, lightning, and CAPE. The land-ocean contrast in lightning activity shows that convective intensity varies between land and ocean independently from convective quantity. Thus, a mechanism that explains the land-ocean contrast must be able to do so even after controlling for precipitation variations. Motivated by the land-ocean contrast, we use idealized CPM simulations to test the impact of the diurnal cycle on high-percentile updrafts. In simulations, updrafts are somewhat enhanced due to large-scale precipitation enhancement by the diurnal cycle. To control for large-scale precipitation, we use statistical sampling techniques. After controlling for precipitation enhancement, the diurnal cycle does not affect convective intensities. To explain why sampled updrafts are not enhanced, we note that CAPE is also not increased, likely due to boundary layer quasi equilibrium (BLQE) occurring over our land area. Analysis of BLQE in terms of net positive and negative mass flux finds that boundary layer entrainment, and even more importantly downdrafts, account for most of the moist static energy (MSE) sink that is balancing surface fluxes. Using ERA-Interim data, we also find qualitative evidence for BLQE over land in the real world, as high percentiles of CAPE are not greater over land than over ocean.
\end{abstract}

\section{Introduction}

Understanding the controls on regional variations in convective intensity is an active problem that is relevant to both the advancement of our science, as well as to human safety. As there are such a variety of potential mechanisms that can control the intensity of convection, it is difficult to separate out the ones that are truly dominant in the real world from the ones that are only potentially relevant. The land-ocean contrast in lightning, shown in Fig. 1a provides some physical intuition toward mechanisms that may influence convective intensity (Boccippio 2002; Williams and Stanfill 2002; Zipser 2003). Despite various well-defined characteristic differences between land and ocean, it is not clear which of these differences is mainly responsible for the lightning or convective intensity contrast. We test one commonly

\footnotetext{
${ }^{\text {a }}$ Current affiliation: School of Atmospheric Sciences, Nanjing University, Nanjing, Jiangsu, China.
}

Corresponding author: Zachary R. Hansen, zrhansen@ nju.edu.cn espoused mechanism for convective intensity regulation, which has not been systematically explored: the impact of the larger diurnal cycle in surface temperature (and heating) over land as compared to over the ocean. We do this through the use of cloud-permitting model (CPM) island simulations, satellite data, and reanalysis data. We show that while the diurnal cycle affects quantities and distributions of large-scale precipitation, it does not impact high-intensity updraft velocity statistics in the CPM simulations, after controlling for large-scale precipitation variations. In contrast, the land-ocean lightning difference in nature persists even after controlling for large-scale precipitation effects.

Lightning is frequently used as a proxy for convective intensity and as a real-time indicator of storm severity and development (Cintineo et al. 2018), due to its positive relationship with many variables associated with convective strength. This is because lightning generation through the noninductive charging mechanism requires frequent collisions of ice and graupel (Takahashi 1978), which occurs most readily in deep convection. Studies on highintensity updraft velocities (Lucas et al. 1994; Boccippio 2002; Zipser 2003; Takayabu 2006; Barthe et al. 2010), 

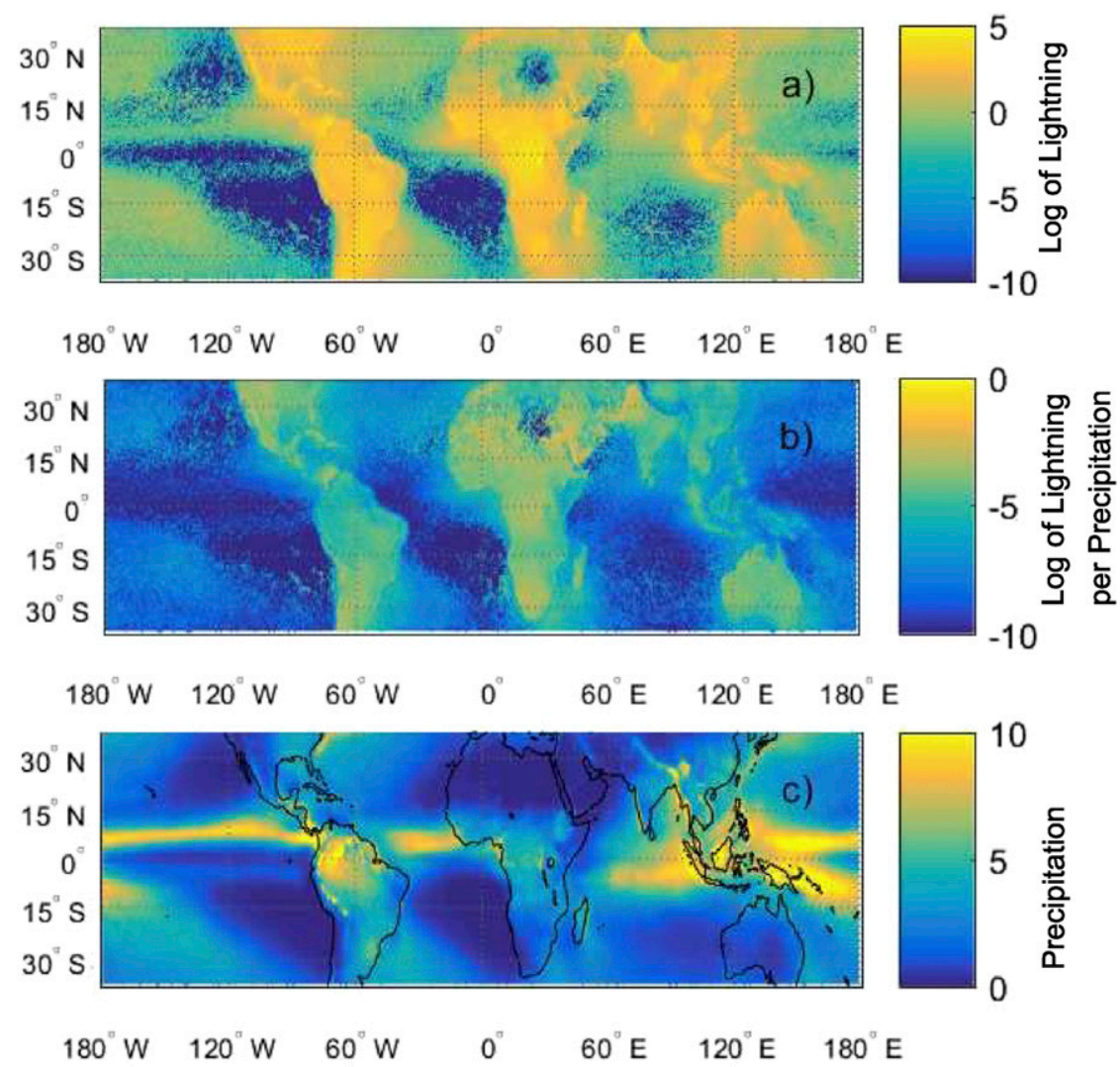

FIG. 1. (a) Map of $\log$ of lightning flash rate $\left[\log \left(\right.\right.$ flash $\left.\left.\mathrm{km}^{-2} \mathrm{yr}^{-1}\right)\right]$. (b) Log of lightning flash rate per unit precipitation $\left[\log \left[\right.\right.$ flash $\left.\mathrm{km}^{-2} \mathrm{yr}^{-1}\left(\mathrm{~mm} \mathrm{day}^{-1}\right)^{-1}\right]$. (c) TRMM 3B42 precipitation $\left(\mathrm{mm} \mathrm{day}^{-1}\right)$. All data are taken as the $2001-08$ average at $0.5^{\circ} \times 0.5^{\circ}$ resolution.

ice quantity and ice mass flux (Petersen et al. 2001, 2005; Deierling et al. 2008; Finney et al. 2014), and graupel flux (Petersen et al. 2005; Barthe et al. 2010) found positive relationships between those variables and lightning flash rate. These variables are related, as more intense updrafts near the freezing-level produce enhancements in mixed-phase precipitation processes (Zipser and Lutz 1994). Ice precipitation amounts also show a nonlinear relationship with lightning flashes from Tropical Rainfall Measuring Mission (TRMM) data (Petersen et al. 2005). As an easily viewable physical proxy for convective intensity, lightning provides intuition toward potential physical mechanisms that influence convection. In this work, we focus on examining the response of 99.99th-percentile 500-hPa updraft velocities to our tested mechanism in CPM simulations, but are motivated by what we observe in lightning maps.

The TRMM's Lightning Imaging Sensor (LIS) shows a clear-cut extreme geographic difference in lightning between areas over land and ocean, with land having orders of magnitude greater lightning flash rate than ocean. It seems plausible that when looking at a map such as Fig. 1a, one might expect the area with the greatest number of storms, potentially associated with the greatest amount of rainfall, to have the highest lightning flash rate. This is not the case for the land-ocean contrast. A simple way to look at convective intensity independently from convective quantity is to divide the convective intensity (mean lightning flash rate) by the convective quantity (mean precipitation) at every grid point, shown in Fig. 1b. It is clear that convective intensity by this metric is still much greater over land than over the ocean. This shows that the land-ocean contrast in lightning is not due to more precipitation over land.

Our use of lightning flash rate per unit precipitation as a proxy for convective intensity is consistent with other work. Williams et al. (2002) used times with higher lightning per unit precipitation to characterize a continental regime, while lower values were used to characterize the Amazon "green ocean" regime. Takayabu (2006) used rain per lightning flash, in conjunction with TRMM data, providing a result in good agreement with our own Fig. 1b.

Climatological precipitation has been known previously to not be a strong control on geographical distributions of lightning, which is instead somewhat regime 
dependent (Williams et al. 1992; Petersen and Rutledge 1998; Petersen et al. 2005). Using statistical sampling techniques in section $4 \mathrm{a}$, we establish more thoroughly that the lightning variations between land and ocean (convective intensity variations) can be viewed independently from convective quantity, even when accounting for the diurnal cycle of large-scale precipitation. This shows that the unknown mechanism(s) explaining the land-ocean contrast do so even after large-scale precipitation variations are controlled.

Controlling for climatological precipitation in our examination of lightning has a potential weakness in that warm-rain precipitation, which does not contribute to lightning generation is included. A more ideal quantity to control for may be ice-phase precipitation, which is more naturally tied to lightning flash rate (as in Petersen et al. 2005). Unfortunately, ice-phase precipitation is not routinely retrieved. This is likely due to the difficulty in accurately assessing the $Z-M$ relationship for individual precipitation events, which can vary greatly (Black 1990). Attempting to calibrate a constant $Z-M$ relationship that applies over land and ocean is beyond the scope of this paper, but could be a potential future direction of research.

One of the most distinctive traits distinguishing a land surface from an ocean surface is that land surfaces have a lower effective heat capacity than ocean surfaces, resulting in an enhanced diurnal cycle in surface temperature. The mechanism we test for the diurnal cycle to influence convective intensity relies on the fact that freetropospheric temperature gradients in the tropics are weak (Charney 1963). Convection over the ocean influences the thermodynamic environment throughout the tropics via gravity wave propagation (e.g., mechanism in Bretherton and Smolarkiewicz 1989; Chiang and Sobel 2002). As SST over the ocean is relatively constant diurnally, anomalously high surface temperatures that occur over land could interact with a free-tropospheric temperature profile influenced by convection with a cooler, oceanic, surface temperature. For a given sounding, warming just the temperature of the lowest levels of a sounding will increase the overall CAPE by shifting the location of the lifting condensation level (LCL) relative to the rest of the profile. If boundary layer relative humidity remains constant, this effect will increase CAPE even more than if boundary layer specific humidity remains constant. Hence, a surface being rapidly heated during the day may interact with a free troposphere where the temperature is essentially constant, due to influences from the tropical ocean: CAPE would be then expected to increase if no other process rapidly counteracts the increased surface fluxes. The mechanism is related to the classic weak temperature gradient (WTG) simulations in Sobel and Bretherton (2000), where, as SST increases, rainfall increases, though those researchers looked at rainfall rather than high-intensity updraft velocities. In this work, we test this mechanism for the diurnal cycle to enhance CAPE and highintensity updraft velocities over land using a partially land domain instead of explicitly imposing WTG to avoid uncertainties in how to best parameterize largescale vertical motion.

CAPE is a ubiquitous variable for predicting the strength of convection, representing the maximum potential buoyancy an air parcel can achieve. Much work investigating the intensity of convection (either in lightning or updraft velocities) relies the assumption that CAPE is a controlling variable (Williams et al. 1992; Williams 1992; Williams and Renno 1993; Singh and O'Gorman 2014). While it is true that updraft velocities of storms in the tropics are heavily influenced by entrainment (Zipser 2003), with no systematic prediction for how entrainment will differ geographically, undilute CAPE remains the natural choice for predicting convective strength. Thus, our investigation of the diurnal cycle's impact on the strength of convection relies on the assumption that said convective intensities (in the form of updraft velocity) will be controlled by CAPE.

Climatological-mean CAPE has previously been shown to be unrelated to lightning (Williams and Renno 1993; Williams et al. 2002). However, if the mechanism we test in this paper were acting, some other quantile, which may occur over the course of a diurnal cycle, may be more relevant for the regulation of convective intensity over land. Romps et al. (2018) did find that CAPE multiplied by precipitation could reproduce land-based lightning, but could not reproduce the landocean intensity contrast. It is entirely possible for mean CAPE over land to be the same as that over the ocean, while having some period during the day that has notably greater CAPE. This would provide evidence that the mechanism we are testing is occurring in the real world. Instead, we find evidence this is not the case in section 5 .

Another distinguishing surface characteristic of land is its higher surface Bowen ratio (the ratio of surface sensible to latent heat flux). Increased boundary layer depth, which is partially determined by the surface Bowen ratio, has been associated with more intense convection. It was thought that this was because deeper boundary layers have wider clouds and thus potentially less environmental entrainment into the convective plume (Lucas et al. 1994; Zipser 2003; Williams and Stanfill 2002; Williams et al. 2005). However, in previous simulations from Hansen and Back (2015), it does not appear that increasing the surface Bowen ratio results in 
enhanced updraft velocities. Those simulations showed little to no dependence of entrainment on boundary layer depth when diagnosed with a parcel model.

Aerosol quantities, and their associated cloud droplet size differences have a similar land-ocean contrast to what we see in the maps of lightning flash rate per unit precipitation (Bréon et al. 2002). Others have also argued that aerosols in combination with normalized CAPE (CAPE divided by the depth of the positive area of the sounding) could explain lighting features using TRMM data (Stolz et al. 2015, 2017). Aerosols were a clear factor in lightning enhancement over ship tracks (Thornton et al. 2017), though it is not clear whether precipitation might have also been enhanced in these regions. Recently, ultrafine aerosol particles have shown an influence on convective updraft velocities in the GoAmazon 2014/15 field campaign, with greater aerosol quantities leading to greater updraft velocities (Fan et al. 2018). However, other work has cast doubt on aerosols being of primary importance, noting that lightning flash rate over land is insensitive to aerosol concentration (Williams et al. 2002; Williams and Stanfill 2002). Others have also shown nonmonotonic relationships between aerosol concentrations and lightning flash rate, making it difficult to diagnose the overall impact of aerosols on the land-ocean contrast in lightning (Mansell and Ziegler 2013).

Physical reasoning suggests that the diurnal cycle in surface temperature over land could influence highintensity updraft velocities, even when accounting for the amount of precipitation. To test whether this occurs, we run CPM simulations with an idealized island over half the domain into radiative-convective equilibrium (RCE; as in, e.g., Parodi and Emanuel 2009) and examine high-percentile updraft velocities while controlling for large-scale precipitation variations. While the island itself is not in RCE, the whole domain is in RCE and the island maintains a statistical equilibrium. We call this land surface an island for convenience due to the periodic boundary conditions that make it surrounded by ocean in the $x$ direction. The island and ocean have the same surface area, so whether it should truly be considered an island or part of a continent is ambiguous. Our ocean's size may be relatively small, but the proposed mechanism should work so long as some amount of oceanic convection occurs.

Islands in general have been shown to enhance both precipitation (convective quantity) and convective intensity in the real world (Sobel et al. 2011) and in CPMs (Robinson et al. 2008, 2011; Cronin et al. 2015; Wang and Sobel 2017). These works have not diagnosed whether the intensity variations [instantaneous precipitation in the case of Sobel et al. (2011) and 99.99th-percentile 500-hPa updraft velocity in the case of Cronin et al. (2015)] are independent of large-scale precipitation amount. Separating the response of convective intensity to various variables including convective quantity has been considered in the past, though not with our focus on highpercentile updraft velocities. Robe and Emanuel (1996) examined mass-flux changes in response to radiation variations, finding that there was a greater mass flux with increased radiative cooling, but this was associated with larger convecting fraction rather than changes in the mean cloudy updraft velocity.

In this study, we control precipitation using statistical techniques that control the mean and whole probability distribution functions (PDF), known as Poisson and stratified sampling, respectively (Särndal et al. 1992, pp. $82,100)$. The noted sampling techniques are also applied to satellite data to see how lightning flash rate changes when the PDF of precipitation is controlled. We find that the land-ocean contrast persists in lightning, but not in the simulations.

Varble et al. (2014) found that many CPMs (including the model we use) overestimate updraft velocities when attempting to reproduce observed convective storms. This is a notable constraint on the usefulness of CPMs. However, our goal is not to reproduce real-world convection, but rather to test the simulations' sensitivity to the mechanisms we propose, all of which are based on physical forcings and mechanisms that should exist in a CPM. Thus, CPM simulations are still an interesting and useful framework to test various mechanisms in isolation. As CPMs are used more broadly due to the availability of more computational power, it is important to note under what circumstances they can reproduce signals seen in observations.

Our satellite data, CPM setup, and reanalysis data are described in section 2. Section 3 explains the two sampling techniques we apply: Poisson and stratified sampling. Section 4 looks at satellite data and CPM results after the two sampling techniques are applied. Section 5 finds that CAPE does not increase with surface heating due to a balance known as boundary layer quasi equilibrium (BLQE; Raymond 1995), and diagnoses specific contributions to that balance. We discuss the implications of our results in section 6. Our final conclusions are presented in section 7 .

\section{Methodology}

\section{a. Satellite data}

Data from TRMM (Simpson et al. 1996) over the period from 2001 to 2008 were used to explore relationships between lightning and precipitation. We used 
orbit files from the TRMM LIS (Cecil et al. 2014), a space-based lightning sensor that is attached to the TRMM observatory, thus its swath data are collocated with the $2 \mathrm{~A} 25$ precipitation product (version 7; Kirstetter et al. 2013). We used data from $40^{\circ} \mathrm{N}$ to $40^{\circ} \mathrm{S}$ averaged onto a $0.5^{\circ}$ grid to produce a time series of precipitation and lightning that included the effects of the diurnal cycle when viewed in a diurnal composite. Note that because TRMM only covers the same location at the same time approximately every 47 days (Simpson et al. 1996), we are not able to view continuous diurnal cycles. Instead, we infer the effects of the diurnal cycle because all times are eventually observed at all locations.

\section{b. Model simulations}

Our simulations were conducted using the System For Atmospheric Modeling (SAM, version 6.10.3; Khairoutdinov and Randall 2003). Our simulations were run in $3 \mathrm{D}$, with $1-\mathrm{km}$ horizontal resolution, 64 vertical levels, and periodic boundary conditions. Our simulations featured a "bowling alley" domain that was $1024 \mathrm{~km}$ in the $x$ direction and $32 \mathrm{~km}$ in the $y$ direction. We utilized the single-moment Lin scheme (Lin et al. 1983) for microphysics, with all parameters kept at their original values. Our diurnal cycle simulations utilized interactive radiative cooling using the Rapid Radiative Transfer Model scheme (Iacono et al. 2000), and a specified sea surface temperature. Subgrid-scale turbulence was parameterized with a Smagorinsky diagnostic closure scheme. A $5 \mathrm{~m} \mathrm{~s}^{-1}$ background wind shear was applied to prevent convective aggregation and allow realistic surface fluxes. The model was run into radiative-convective equilibrium for all cases, taking approximately 40 days. Another 25 days were left to collect statistics. All statistics were gathered at a 30-min sampling interval, either using instantaneous snapshots or time average.

The left half of the simulation domain had a diurnally oscillating sea surface temperature (SST) from $295 \mathrm{~K}$ at midnight to $305 \mathrm{~K}$ at noon; this represented our island area. While for some purposes it is desirable to perform simulations with a land surface model, our setup intentionally contains only the ingredients necessary to test the mechanism we are examining. The island is highly idealized in that its only distinguishing trait is the diurnal cycle in surface temperature. Things like topography, surface roughness, or evaporative conductance (affecting Bowen ratio) were not changed from their base oceanic values. The right half of our domain had a fixed SST of $300 \mathrm{~K}$, representing the ocean portion. One could run this style of simulation with a simple land surface model as well, but we do not expect that would change our main conclusions. Understanding what is happening in such simulations would be more challenging once cloud shading by convection became involved, so we chose to idealize the surface for ease of analysis and simulation setup.

For the analysis of convective updrafts, as well as mixing processes in the boundary layer, $1-\mathrm{km}$ horizontal resolution is still somewhat coarse (Stevens et al. 1999; Bryan et al. 2003). However, qualitative results from Hansen and Back (2015) were insensitive to resolution, and preliminary results in this simulation setup at 500-m resolution also appear to be qualitatively similar. We also tested a simulation with a diurnal cycle that was twice what we show in this paper, with similar qualitative results.

\section{c. Reanalysis data}

To examine whether real-world CAPE is being amplified over land by the diurnal cycle in surface heating, we used 6-hourly (to include at least some of the effects of the diurnal cycle) ERA-Interim data to build a PDF of CAPE from the period 2001-08. The CAPE calculation was performed pseudoadiabatically from the surface on $\eta$ coordinates to ensure that interpolation was not occurring below the physical surface in the model data. Calculating adiabatic CAPE did not qualitatively change the results. CAPE was calculated as in Riemann-Campe et al. (2009), except that we compiled all individual times rather than taking time averages.

\section{Sampling techniques}

\section{a. Poisson sampling}

To account for differences in precipitation from various simulations, or in the case of our diurnal cycle simulations, from different regions of a specific simulation, a statistical sampling technique called Poisson sampling can be applied (Särndal et al. 1992, p. 82). In our case, we desire to have domain-mean (area of the island or ocean rather than total domain) precipitation be the same over the island and ocean, with ocean as our control, and explore how high-intensity updrafts respond under that constraint.

To alter the domain-mean precipitation, we sample by modifying the proportion of domain-mean precipitation times (called large-scale precipitation from here on) sampled. Naturally, there will be times that have higher or lower land-mean precipitation than that of the oceanic mean. We adjust our island's overall mean precipitation by oversampling times that have lower precipitation means and undersampling times that have higher precipitation over the land area. There is a known 
relationship that instantaneous local (gridpoint) precipitation is strongly tied to local convective intensity (e.g., Muller et al. 2011). However, we are interested in the response of convective intensity to changing the mean precipitation on the scale of our island rather than the local precipitation. In simulations, we mainly examine convective intensity in terms of the 99.99thpercentile $500-\mathrm{hPa}$ updraft velocity. We use this percentile because it represents the upper tail of the updraft velocity distribution, but is still well sampled in model simulations. The $500-\mathrm{hPa}$ level was chosen because it is typically slightly colder than $0^{\circ} \mathrm{C}$, and the connection between updrafts and lightning flash rate is related to both ice collisions (Takahashi 1978) and ice generation (Sullivan et al. 2016). We use Poisson sampling to reweight our samples drawn from our simulations, and the procedure can be generalized as follows:

The variables that go into this algorithm are the total number of local samples we want to take $N$, which will be used to form a cumulative distribution function (CDF) of updraft velocities, and the specified mean precipitation value $P_{o}$ of the control region. We also take two groups from the noncontrol region, whose mean precipitations are above $P_{\mathrm{abv}}$ and below $P_{\mathrm{blw}}$ the specified value $P_{o}$. To reiterate, these two groups are sorted by area-averaged island-mean values rather than local values; each distribution, $P_{\mathrm{abv}}$ and $P_{\mathrm{blw}}$ will have local values that fall above and below $P_{o}$. To find the number of samples we want to take from each respective group, we use the following equations:

$$
\frac{A P_{\mathrm{abv}}+B P_{\mathrm{blw}}}{N}=P_{o}
$$

where $A$ and $B$ are the number of local samples from their respective groups. Thus, the sum of $A$ and $B$ should equal $N$. So, we substitute $B$ for $N-A$ and solve for $A$ :

$$
A=\frac{N\left(P_{o}-P_{\mathrm{blw}}\right)}{P_{\mathrm{abv}}-P_{\mathrm{blw}}} .
$$

Note that both $A$ and $B$ need to be whole numbers because it is a quantity of samples that we are taking, so we round both $A$ and $B$ to the nearest integer. This does not affect our results because rounding error is small relative to the number of total samples. We use sample sizes on the order of 10000000 . Once we have found how many samples to take from each of the two groups, we take local samples of updraft velocity associated with the island-mean precipitation from the two groups above, with sample counts $A$ and $B$. This allows us to form a new updraft velocity $\mathrm{CDF}$ that has the same mean precipitation as the ocean.
The explicit goal of our Poisson sampling is to examine what impact the diurnal cycle has when mean precipitation is the same for both our island and ocean. To show how this process affects the distribution of our Poisson-sampled data, we describe the statistical model as follows (using our diurnal cycle simulations as an example):

$$
w=f_{\text {island }}(P)+\varepsilon,
$$

where $w$ is convective intensity (explicitly, some high percentile of updraft velocity), $f_{\text {island }}(P)$ is the functional relationship between large-scale precipitation and convective intensity, and $P$ is precipitation over larger scales. This equation can be used to represent the null hypothesis of our experiments: If, after controlling for large-scale precipitation, $w$ is the same between island and ocean, then the null hypothesis that only large-scale precipitation determines updraft velocities cannot be falsified. Here, $\varepsilon$ represents other variables that could influence convective intensity that are not related to large-scale precipitation. If the null hypothesis holds, then $\varepsilon$ must have mean zero (over a time scale longer than the diurnal cycle) and finite variance, so that we are not selectively sampling for certain $\varepsilon$ values when performing our Poisson sampling. Equation (3) would then state that difference in convective intensity between island and ocean is only controlled by precipitation (in the sense that $w$ is tightly correlated with $P$ ), something that is not true in reality.

\section{b. Stratified sampling}

Poisson sampling forces the mean of a variable to be the same in both cases, but allows the shape of the precipitation distributions to be different. Stratified sampling can be used to force the entire distribution of large-scale precipitation to be the same between cases (Särndal et al. 1992, p. 100). Stratified sampling helps to identify explanatory variables effectively, while limiting the impact of confounding variables (Imbens and Lancaster 1996), something that causes difficulties in Poisson sampling.

By stratified sampling, we can force the large-scale precipitation distribution to be the same over both the island and ocean. Since it has been observed that $P$ and $w$ are higher over islands than ocean, we introduce the stratified sampling method that can draw subsamples from $P_{\text {island }}$, to have the same overall distribution of $P_{\text {ocean }}$, and test whether the distribution of $w_{\text {island_sub }}$ is same as $w_{\text {ocean }}$. If $w_{\text {island_sub }}$ is unchanged following the sampling, then we can conclude that precipitation and updraft velocity are following the same relationship over land and ocean in our model. This is something that we 

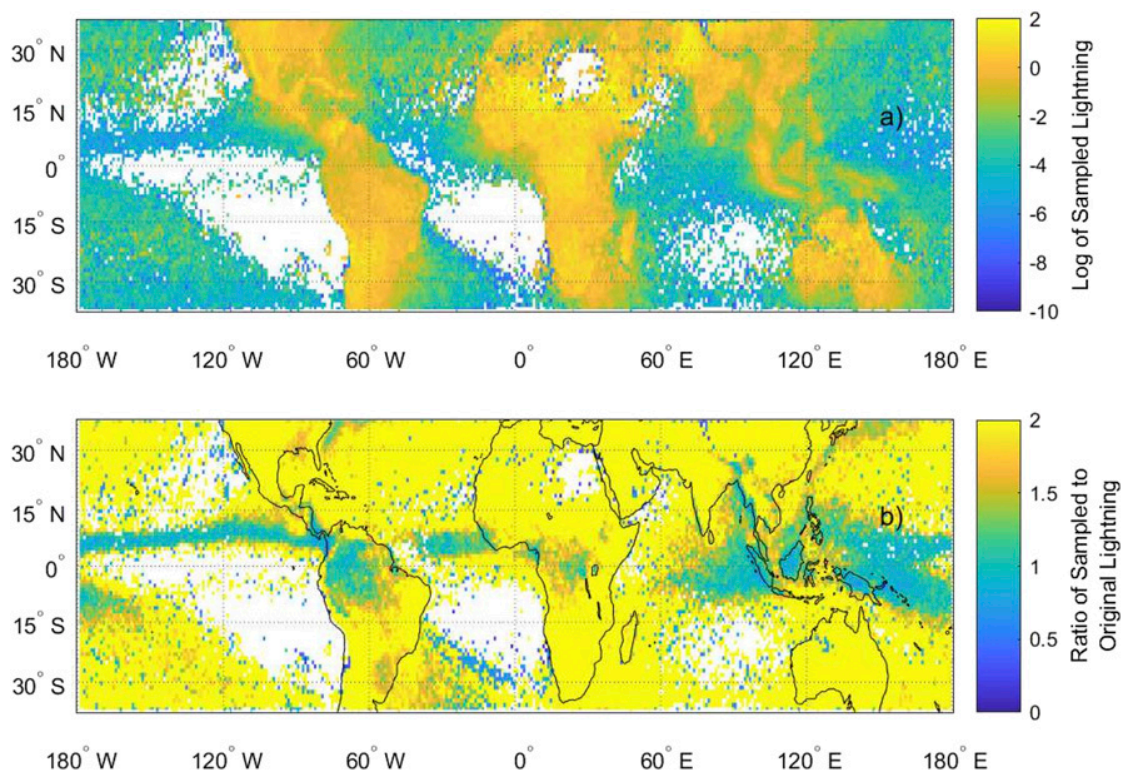

FIG. 2. (a) Lightning flash rate where every grid point has the same mean precipitation via Poisson sampling [ $\log \left(\right.$ flash $\left.\left.\mathrm{km}^{-2} \mathrm{yr}^{-1}\right)\right]$. (b) Ratio of Poisson-sampled lightning to unadjusted lightning in Fig. 1a. The Poisson-sampled lightning was taken with mean precipitation from the west Pacific warm pool $\left(5^{\circ} \mathrm{N}-5^{\circ} \mathrm{S}, 160^{\circ} \mathrm{E}-180^{\circ}\right)$, approximately $6 \mathrm{~mm}$ day ${ }^{-1}$. White locations represent grid points that did not have precipitation samples required to achieve the mean precipitation specified.

know is not true for lightning and precipitation in the real world (see section 4a).

To perform stratified sampling, we first isolate our data into space $(i)$, time-mean $(t)$ combinations, $\left\{\left(w_{i}, p_{t}\right)\right\}^{\text {island }}$, $\left\{\left(w_{i}, p_{t}\right)\right\}^{\text {ocean }}$, and define bins of $p_{t}$, with $K$ being our total number of bins over some intervals of precipitation. We use $1 \mathrm{~mm} \mathrm{day}^{-1}$ bins from 0 to $23 \mathrm{~mm}$ day $^{-1}$. We calculate the likelihood of occurrence $r$ that a mean precipitation $\left(p_{t}\right)^{\text {ocean }}$ falls into a certain bin. Using these probabilities, we resample from $\left(p_{t}\right)^{\text {island }}$, so that it has the same distribution of precipitation as that of $\left(p_{t}\right)^{\text {ocean }}$ to create $\left(p_{t}\right)^{\text {island_sub }}$. As $\left(w_{i}\right)^{\text {island }}$ is some function of $\left(p_{t}\right)^{\text {island }}$, we will see how the relationship between these two distributions changes when we sample $w$ from $\left(p_{t}\right)^{\text {island_sub }}$, creating $\left(w_{i}\right)^{\text {island_sub }}$. If $\left(w_{i}\right)^{\text {island_sub }}$ is the same as $\left(w_{i}\right)^{\text {ocean }}$, we can say that there is no difference in the functional relationship between precipitation and updraft velocity over the island compared to over the ocean (our null hypothesis).

\section{Results}

\section{a. Satellite data}

Using the TRMM 2A25 and LIS data discussed in the methodology, we apply both of the mentioned sampling techniques to illustrate that lightning contrasts in the real world are not determined by climatological precipitation values. It will be clearly shown that the land-ocean contrast in lightning in the real world is fundamentally independent from large-scale precipitation. This is in stark contrast to our model simulations, where the 99.99th-percentile of 500-hPa updraft velocity is almost completely determined by the large-scale precipitation amount. A working mechanism for convective intensity modulation that could explain the land-ocean contrast would be able to produce a response similar to what we see in the satellite data.

We use Poisson sampling to compare the lightning map in Fig. 1b, where each location has its mean lightning flash rate divided by its mean precipitation rate to a new map where each grid box has the same mean precipitation. Note that we are using approximately instantaneous time values, but the precipitation is implicitly averaged over a $0.5^{\circ} \times 0.5^{\circ}$ box, giving us a largescale precipitation value, similar to our modeling results in section $4 \mathrm{~b}$. We chose a region on the edge of the west Pacific warm pool $\left(5^{\circ} \mathrm{N}-5^{\circ} \mathrm{S}, 160^{\circ} \mathrm{E}-180^{\circ}\right)$, which had relatively high precipitation and low lightning as our control area. We then Poisson sampled every location such that they had the same mean precipitation value as that control region, approximately $6 \mathrm{~mm} \mathrm{day}^{-1}$. Shown in Fig. 2a, this sampled lighting map looks similar to the lightning per unit precipitation map in Fig. 1b. Sampled lightning over land generally increases after Poisson 

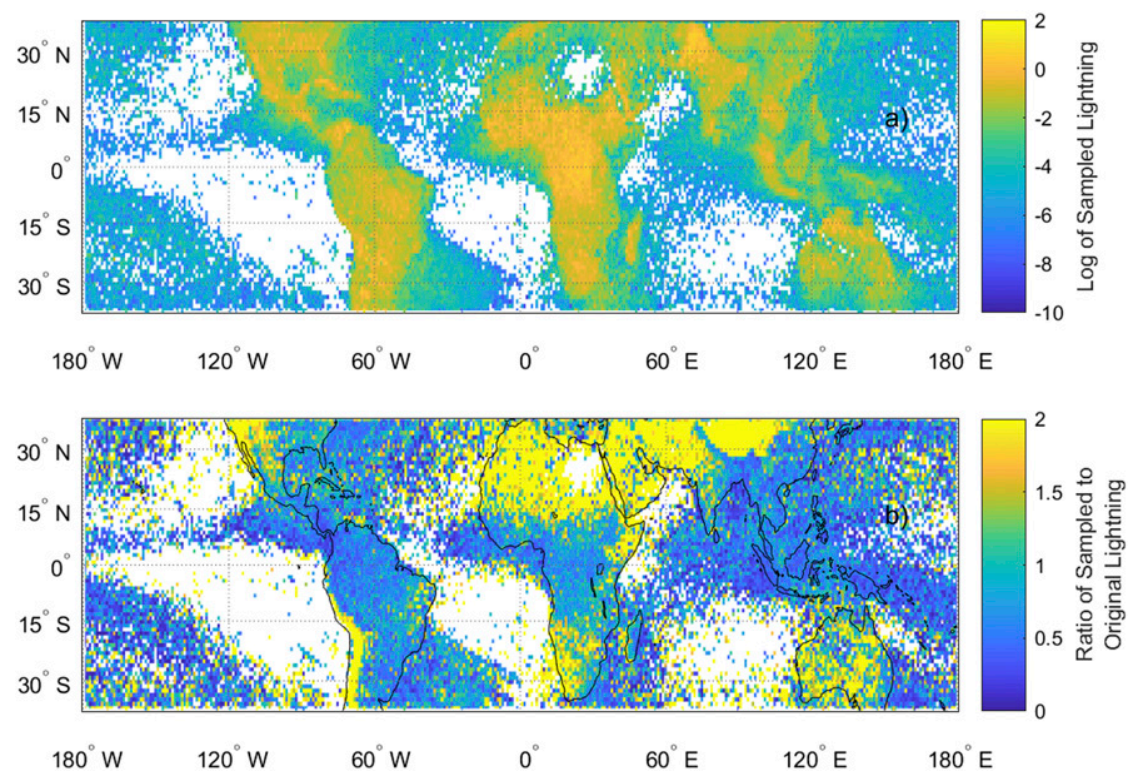

FIG. 3. (a) As in Fig. 2a, except that now stratified sampling has been applied in place of Poisson sampling. Each grid point has the same precipitation PDF, again using the west Pacific warm pool region as the control. (b) Ratio of the stratified-sampled lightning flash rate to the unadjusted lightning flash rate. White locations represent grid points that were unable to fill in the entire precipitation PDF specified.

sampling, as Fig. 2b shows the ratio of Poisson-sampled lightning flash rate to the true flash rate in Fig. 1a. This is because most regions over land have less precipitation than our control region, so we are sampling more storms when creating the Poisson-sampled lightning-flash-rate map. The land locations that did experience modest decreases in lightning were predominantly in the tropics, namely the Amazon "green ocean" regions, as well as portions of central and West Africa.

Given that lightning is expected to occur in more intense storms (which have higher instantaneous rain rates), we expect continents to have different large-scale precipitation distributions from oceans, even if mean precipitation values may be similar. At least some of this precipitation difference should be contributed by the diurnal cycle in surface heating. Thus, we examine how lightning over land responds when given a more oceanic precipitation distribution. It is likely that we are not only exploring the impact of the diurnal cycle when performing stratified sampling on our satellite data, as there are other mechanisms that also cause differences in the precipitation PDF between land and ocean.

We use the same representative region as in the above Poisson sampling, except that we now consider the regions precipitation PDF rather than precipitation mean. Then we resampled every grid point's precipitation and associated lightning so that the precipitation would match the representative PDF that we chose. After sampling, the general map of stratified-sampled lightning in Fig. 3 looks similar to that of Figs. 1a and 2a. However, the sampled lightning count has decreased compared to initial and Poisson-sampled values. This is shown in Fig. 3b, which gives the ratio of stratified-sampled lightning count to unadjusted lightning count. Over tropical continent areas, lightning has decreased notably, with the new values being $50 \%-60 \%$ of what they were previously. There were also smaller regions with decreases up to $70 \%$. This does not change the overall nature of the land-ocean contrast because flash rates over land were at least two orders of magnitude larger than those over the ocean.

The diurnal cycle in surface heating likely contributes to differences in precipitation PDF between land and ocean. A landlike precipitation PDF gives more lightning than an ocean-like one, but differences in precipitation PDF are not the main reason for the land-ocean contrast in lightning, as a large lighting contrast still exists after sampling.

\section{ON WHAT SCALE DOES LIGHTNING ENHANCEMENT OCCUR?}

An important question relevant to our model simulations and real-world convective intensity contrasts is the land size scale for which lightning becomes enhanced. We want to ensure that our simulated island is large enough that it can be expected to produce 


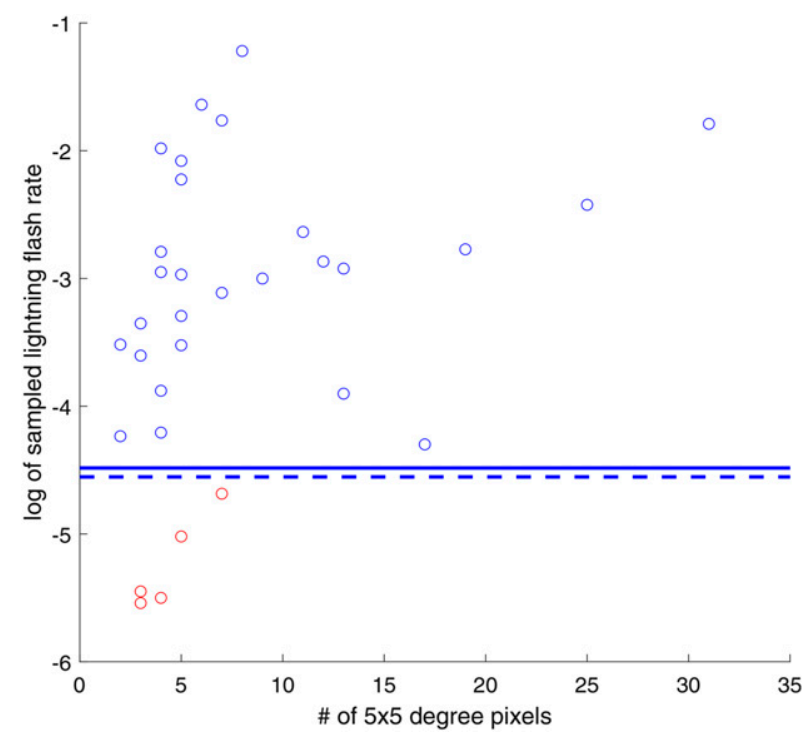

FIG. 4. A comparison of island-sampled lightning flash rates and ocean-mean lightning flash rate (total ocean is solid blue line; west Pacific warm pool area as defined above is dashed blue). Blue dots represent areas with sampled lightning greater than the ocean mean; red dots have sampled lightning less than ocean mean. Every location has been given the same mean precipitation distribution via stratified sampling. The $x$ axis is island size in number of pixels, while the $y$ axis is log of lightning flash rate.

convective intensity increases if the proposed mechanism were to hold. Williams et al. (2004) found that islands tend to show more continental convective qualities as they approach sizes of $1000 \mathrm{~km}^{2}$. Our model simulation's island was $512 \mathrm{~km} \times 32 \mathrm{~km}$, approximately $15000 \mathrm{~km}^{2}$. Given periodic boundary conditions on the $y$ axis of our island it also makes sense to think of it as having at least a $512-\mathrm{km}$ diameter. The goal of this section is to confirm that lightning enhancement occurs at least on the scale of our island, and preferably on somewhat smaller scales as well.

Using our sampled lightning dataset where stratified sampling has been applied so that every location has the same precipitation distribution, we isolated all islands smaller than $75000 \mathrm{~km}^{2}$ (32 islands total), with the minimum size being $0.5^{\circ} \times 0.5^{\circ}$, or approximately $2500 \mathrm{~km}^{2}$. We found that nearly all islands examined showed at least some lightning enhancement compared to oceanic values, as shown in Fig. 4. There were five islands that had lower sampled lightning flash rates compared to mean ocean values after stratified sampling: the Hawaiian chain (counted as one island due to grid resolution), Tahiti, Cape Verde, Mauritius, and North Island (New Zealand). It is not clear why these islands specifically did not produce enhanced convection. Our model simulation's island is larger than the smallest islands producing convective enhancement by
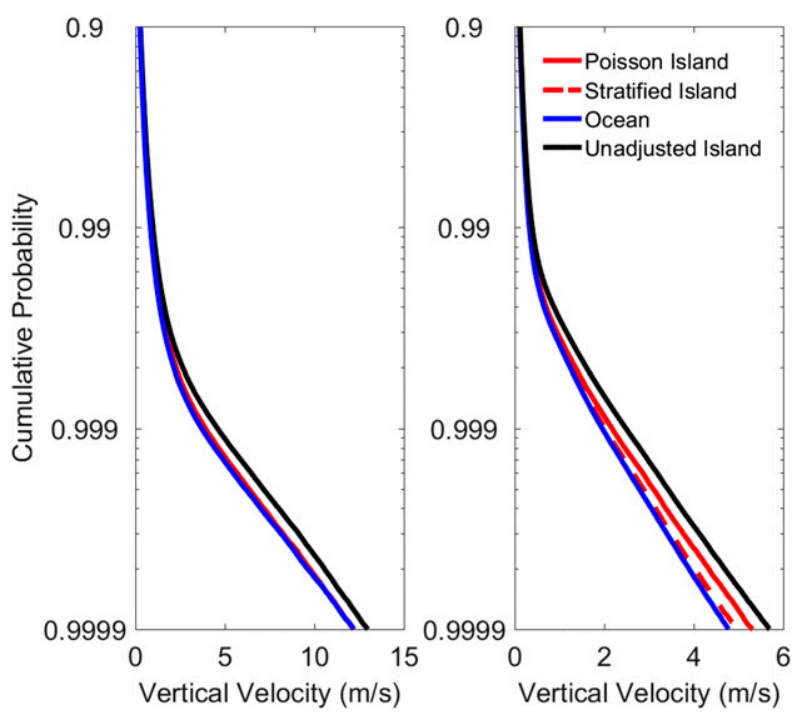

FIG. 5. Cumulative distribution functions of 500-hPa vertical velocity. (left) Instantaneous snapshots of unadjusted updraft velocity over the island (black), Poisson-sampled island updraft velocity (red), and ocean updraft velocity (blue). (right) Time-averaged output (30-min sampling), where colors are as in the left panel, while the red dashed line represents the binomial-sampled island updraft velocity. Note that going down the $y$ axis increases in intensity; 0.9999 is equivalent to the 99.99th percentile.

this analysis, and we would expect any diurnal cycle surface heating mechanism present on real-world scales to be present on our island's scale as well.

\section{b. Diurnal cycle simulations}

Our diurnal cycle simulations show enhanced precipitation over the island at times of high surface temperature, similar to Cronin et al. (2015) and Wang and Sobel (2017). The diurnal-mean precipitation over the island $\left(3.9 \mathrm{~mm} \mathrm{day}^{-1}\right)$ is slightly higher than the mean precipitation over the ocean $\left(3.5 \mathrm{~mm} \mathrm{day}^{-1}\right)$, though the times of enhanced surface heating have island-mean precipitation up to $9.3 \mathrm{~mm}$ day $^{-1}$ at time of day (TOD) 1430. Before applying Poisson sampling, 500-hPa highpercentile updraft velocities (99.99th percentile) are greater over the island than they are over the ocean, as shown in the black line on the left side of Fig. 5.

We expect that a mechanism acting to increase CAPE would produce stronger high-intensity updrafts for a given large-scale precipitation value. To examine whether this is the case in our simulations, we performed Poisson sampling so that our simulation's island has the same mean precipitation as its ocean. The red line on the left side of Fig. 5 is the island's 500-hPa updraft velocity when the mean precipitation over the island is the same as that over the ocean. With instantaneous snapshots as our output method, there is no convective intensity 
contrast after performing Poisson sampling to account for differences in convective quantity.

It is important to remember that the Poisson-sampled CDF shown in Fig. 5 is not the actual CDF of our data. It is possible for convection to vary in intensity over the course of the day, even when controlling for our mean precipitation. Thus, we also tested whether there are particular times of day when updraft velocities are systematically enhanced and found no significant enhancement.

We also examined the impact of the diurnal cycle on ice water path (IWP), defined in this case as the integrated precipitation water colder the $-10^{\circ} \mathrm{C}$. We again use Poisson sampling to compare the island and ocean regions when their large-scale precipitation values are equal. Prior to Poisson sampling, mean IWP over the island was $0.030 \mathrm{~kg} \mathrm{~m}^{-2}$ and mean IWP over the ocean was $0.021 \mathrm{~kg} \mathrm{~m}^{-2}$. We also examined the conditional IWP, where the IWP with values of $0 \mathrm{~kg} \mathrm{~m}^{-2}$ are removed. Prior to sampling, mean conditional IWP was 0.178 over the island, and 0.139 over the ocean. These conditional IWP differences could lead to nearly a factor-of-2 difference in lightning flash rate (Petersen et al. 2005). After Poisson sampling, mean IWP over the island was $0.024 \mathrm{~kg} \mathrm{~m}^{-2}$, and mean conditional IWP was $0.144 \mathrm{~kg} \mathrm{~m}^{-2}$. These differences are much less, and could only partially at best explain a land-ocean contrast in lightning.

\section{TIME-AVERAGED OUTPUT}

Our time-averaged output was taken from the same simulation as the instantaneous case mentioned above and was run so that statistics were averaged over $30 \mathrm{~min}$ rather than being output as instantaneous snapshots. Shown on the right side of Fig. 5, Poisson-sampling results still show stronger updraft velocities with the island simulations.

This change in the response of high-percentile updraft velocity to Poisson-sampled precipitation may imply a change in the PDF of precipitation following time averaging. This can be explained by considering two cases, one case where precipitation has two values, zero and $x$ that are randomly distributed, and another case where the values are separated such that all the $x$ values are adjacent to another $x$ value. In both cases the average value of the domain is the same. However, if one were to coarsen the distribution by a running average, the first case would have many values of $0.5 x$, while the second case would still be stratified into zeros and $x$ values. The mean value of these two groups would still be the same as well. However, when looking at the extremes of the coarsened distributions, it would appear as though the second case had larger values.
This sort of occurrence seems probable in our simulations: the temporal distribution of convection over our island is tightly constrained by the diurnal cycle, while over the ocean, there is less of a temporal constraint. To investigate the impact of these changes in the PDF of large-scale precipitation when time averaging, we apply stratified sampling, which controls for the entire PDF of the distribution.

We applied stratified sampling to our model data by having the ocean portion of the domain give a characteristic large-scale precipitation PDF to use as a control. When performing stratified sampling on our instantaneous output, we found a result identical to that of our Poisson-sampled simulations. However, when stratified sampling is performed on the time-averaged results, we get a notable difference. The red dashed line on the right side of Fig. 5 shows that after stratified sampling, high-percentile updraft velocities match those of the ocean much more closely. Using stratified sampling, we illustrate that convection over our island is more temporally organized than over our ocean, but this organization does not enhance high-intensity updraft velocities.

When comparing the model results to those of the satellite data above, it is worth noting that the satellite data does not have an explicit time average. When assembling each orbital pass for output, there is some inherent spatial and time averaging that may result in the differences in precipitation PDF similar to those seen in the model data. However, the satellite data result was mainly controlling for instantaneous large-scale differences in precipitation, rather than for the effects of time averaging.

\section{Boundary layer quasi-equilibrium response to the diurnal cycle mechanism}

The premise of the diurnal cycle mechanism was that surface heating over land could interact with a free troposphere that was influenced by oceanic convection associated with a cooler surface temperature. This mechanism had been proposed to produce greater CAPE over the island compared to over the ocean. We calculated the surface-based pseudoadiabatic CAPE to $500 \mathrm{hPa}$, as buoyancy above that level would not contribute to $500-\mathrm{hPa}$ updraft velocities. Integrating through the whole troposphere does not change the qualitative result. This CAPE over the island was approximately the same as over the ocean at times of peak SST as well as at times of peak island precipitation, shown in Fig. 6a. There is a period in the morning when CAPE is higher over the island, but as precipitation is not occurring during those times and does not develop for another 

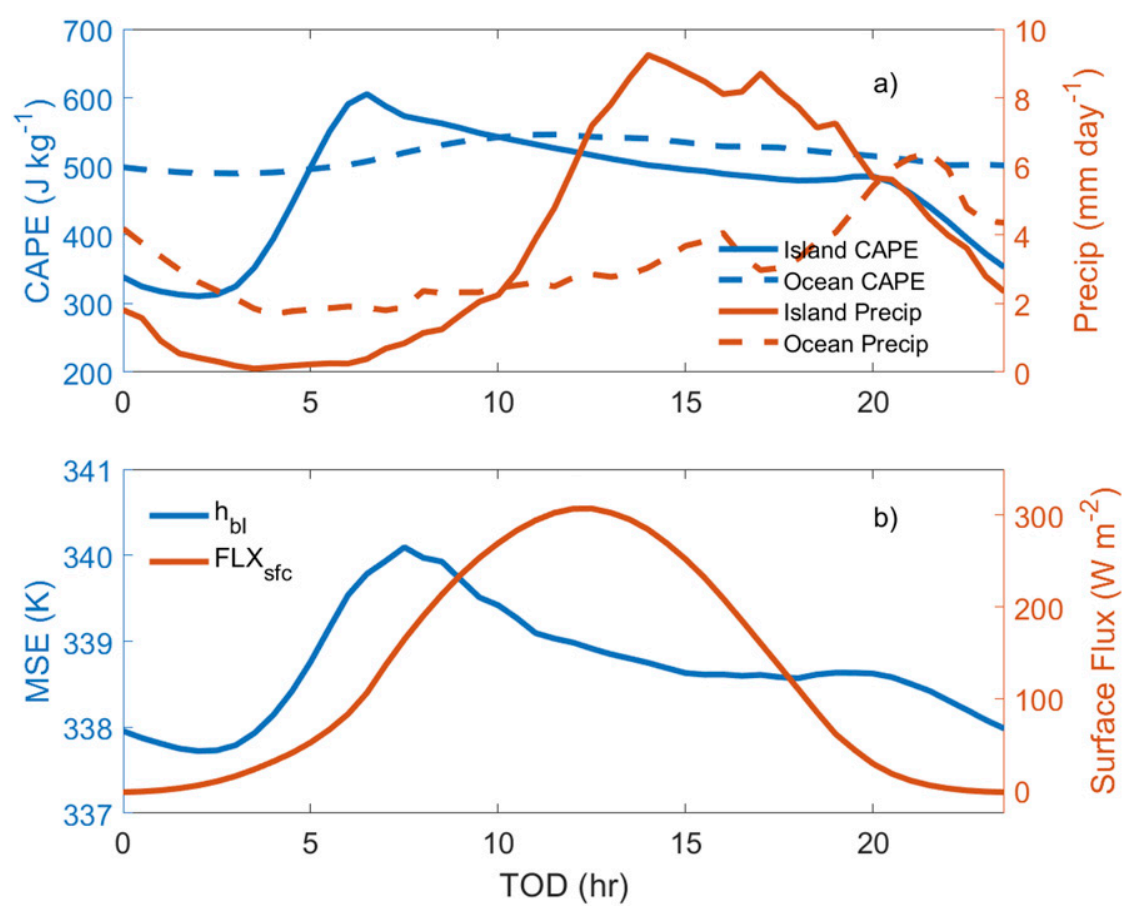

FIG. 6. (a) Comparison of island and ocean CAPE integrated to $500 \mathrm{hPa}$ (left $y$ axis) to island and ocean precipitation (right $y$ axis). (b) Island boundary layer mean moist static energy $h_{\mathrm{bl}}$ (left $y$ axis) compared to island surface fluxes $\mathrm{FLX}_{\text {sfc }}$ (right $y$ axis). All data are composited into a 24-h diurnal cycle using 25 model days.

few hours, we do not consider it to be relevant to our tested mechanism.

CAPE does not increase because boundary layer MSE is not increasing with surface fluxes, as seen in Fig. $6 b$. Oceanic convection is affecting the free-tropospheric temperature profile, which changes very little throughout the day, shown in Fig. 7. The daytime temperature increase over the island is relatively small, approximately $3 \mathrm{~K}$, though if either moisture or relative humidity had stayed constant, we would still have seen significant CAPE growth. Because boundary layer temperature does respond to our surface heating, decreases in boundary layer moisture are why the boundary layer MSE does not increase with heating.

Given that there is a strong surface flux acting to increase the MSE of the boundary layer and that our boundary layer's mean MSE is not increasing, there must be some compensating flux that is acting to decrease the boundary layer's MSE, which is defined as

$$
h=c_{p} T+g z+L_{v} q,
$$

where $h$ is the moist static energy, which is the sum of temperature $T$ multiplied by the specific heat capacity of dry air $c_{p}$, geopotential $g z$, and water vapor $q$ multiplied by the latent heat of vaporization $L_{v}$.
A result of Fig. $6 \mathrm{~b}$ is that there must be some compensating flux to prevent our boundary layer's MSE from increasing. Raymond (1995) and Emanuel (1995) introduced the concept of boundary layer quasi equilibrium,

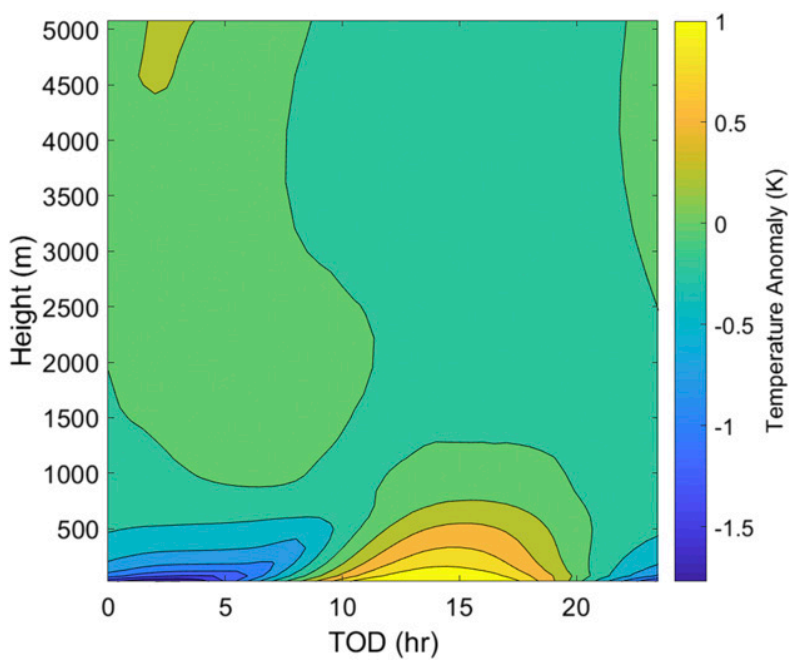

FIG. 7. Composite diurnal cycle of the temperature anomaly (K) of each vertical level over the total island area for the first vertical $5000 \mathrm{~m}$ of the domain. Contours are every $0.25 \mathrm{~K}$. Data have been collected in the same manner as the previous simulation figures. 
in which fluxes from an ocean surface were proposed to have been compensated by convective downdrafts from the free troposphere, which acted to keep the boundary layer's mean equivalent potential temperature approximately constant. Raymond et al. (2006) also used a full boundary layer moist entropy analysis to examine contributions to BLQE in a less idealized setting than Raymond (1995). The existence of a compensating flux preventing MSE from increasing over our island's boundary layer means that BLQE is occurring in our simulation as well.

To examine how the contributions to BLQE are changing throughout the course of the diurnal cycle in our simulations, we use a boundary layer MSE budget. This is a natural choice in our case, as gridded model data allow us to directly examine every variable that contributes to MSE at high resolution. Additionally, because the free-tropospheric temperatures in our simulation are relatively constant, a boundary layer MSE budget essentially represents a budget for CAPE in our simulations. Our case is different from the ones described above: there is a well-defined diurnal cycle in surface heating. However, despite this difference, the general principles of our analysis should be the same, and can be applied to real-world land surface boundary layers as well. Our BLQE event is also notable because the predicted time scale for the balance in Raymond (1995) and in Raymond et al. (2015) was about $12 \mathrm{~h}$, while ours occurs much more rapidly, as CAPE is not increasing during the majority of the day, including times when surface temperatures are high.

The basic form of the boundary layer MSE budge equation is as follows:

$$
\frac{\frac{d}{d t} \iiint h d V+\oint h \mathbf{v} \cdot d S}{d V}=F+Q_{r}+R,
$$

where $h$ is the moist static energy, $V$ is the volume of the island boundary layer, $S$ is the surface through which vector integration occurs, and the right-hand-side terms consist of the surface fluxes $F$, the boundary layer radiative flux divergence $Q_{r}$, and a residual $R$, which is mainly associated with the fact that we are using temporal snapshots every $30 \mathrm{~min}$. This budget will allow us to diagnose the individual sources and sinks of MSE to the boundary layer in our simulations.

The first term on the left-hand side is the time rate of change of the mean boundary layer MSE integrated throughout the whole volume. Note that the boundary layer is changing in depth with time, and we calculate the depth assuming that the boundary layer is well mixed, and that our parcel is lifted from the second model level, with the boundary layer top in this case being defined as the lifting condensation level. The second model level is chosen because the LCL determined from that level matches most closely with physical cloud base in our simulations.

The second term on the left-hand side is the surface integral capturing flow into and out of the boundary layer from the sides and top, with the flow at the top being relative to the rate of change of boundary layer growth. Expansion of this surface integral is composed of four terms that can be separated into three components:

$$
\begin{aligned}
\oint h \mathbf{v} \cdot d S= & \int_{0}^{n_{z} \Delta z} \int_{0}^{n_{y} \Delta y} u_{L} h_{L} d y d z-\int_{0}^{n_{z} \Delta z} \int_{0}^{n_{y} \Delta y} u_{R} h_{R} d y d z \\
& -\int_{0}^{n_{y} \Delta y} \int_{0}^{n_{x} \Delta x} \bar{w} \bar{h} d x d y-\int_{0}^{n_{y} \Delta y} \int_{0}^{n_{x} \Delta x} w^{\prime} h^{\prime} d x d y .
\end{aligned}
$$

The first two terms on the right-hand side of Eq. (6) represent MSE advection associated with flow into and out of the sides, where the subscript $L$ and $R$ represent position $(0.5, y, z)$ and $(512.5, y, z)$, respectively; $n$ represents the number of grid points in a given direction and $\Delta$ represents the grid spacing. The third term represents the flux of mean MSE air at the top of the boundary layer, with the mean values calculated as $\bar{h}=\int_{0}^{n_{y}} \int_{0}^{n_{x}} h d x d y /\left(n_{x} n_{y}\right)$ with the same process used to calculate $\bar{w}$. The fourth term represents the eddy flux of MSE associated with the covariance from Reynolds decomposition:

$$
w h=\overline{w h}+w^{\prime} h^{\prime},
$$

where $w h$ is the total instantaneous MSE flux, mean values are calculated as described above, and $w^{\prime}$ and $h^{\prime}$ are the perturbations relative to the mean that describe the covariance when multiplied together.

We are interested in which components of the flow are contributing most to the balance of MSE in our boundary layer. For illustrative purposes, we then reorganize Eq. (5) into the specific components discussed above:

$$
\frac{d h}{d t}=F+Q_{r}+K-w^{\prime} h^{\prime}+R
$$

The left-hand side is the time rate of change of boundary layer MSE. The first two terms on the righthand side are the same as the right-hand side in Eq. (5), and $K$ represents the first two components of Eq. (6) discussed above, the total flow into the boundary layer from the sides subtracted by the flux of mean MSE at the LCL. The following term $w^{\prime} h^{\prime}$ is the eddy flux of MSE. 
We also include the residual term discussed above. This budget is similar to the one discussed in Eq. (3) of Raymond et al. (2006), though our notation is somewhat simplified.

We composite these terms into a single diurnal cycle in Fig. 8. The boundary layer MSE does initially increase as surface fluxes increase; however, the eddy flux dries our boundary layer (BL) throughout the day, keeping MSE nearly constant. All other terms are small in comparison. This shows that contributions from outside our island area are not very relevant to the maintenance of BLQE in our simulations.

Our goal is to separate out the contributions from the areas of net upward and downward mass flux over our island domain associated with the eddy covariance of moist static energy at the top of the boundary layer $\left(w^{\prime} h^{\prime}\right)$. Sorting by MSEs associated with negative and positive net mass flux elegantly removes the impact of gravity waves, leaving the MSE fluxes we are actually concerned with. In this perspective, MSEs with negative net mass flux can contribute to entrainment and downdrafts, while MSEs with positive net mass flux can only contribute to updrafts as a way to maintain BLQE.

Using an isentropic streamfunction analysis as in Pauluis and Mrowiec (2013), we can identify the critical MSE for this mass flux separation by calculating the isentropic streamfunction $\psi$ at our LCL:

$$
\psi_{\mathrm{lcl}}\left(z_{\mathrm{lcl}}, h\right)=\int_{-\infty}^{h} \rho w\left(z_{\mathrm{lcl}}, h^{\prime}\right) d h^{\prime}
$$

This equation gives the net mass flow per unit area for all air parcels with an MSE less than $h$, which is the mean MSE at the top of the boundary layer (slightly different from the mean boundary layer MSE). Finding the MSE associated with the absolute minimum streamfunction value identifies the sign change in net mass flux. MSEs lower than the $\psi_{\mathrm{lcl}}$ minima have a total negative net mass flux, while all higher MSEs have a total positive net mass flux.

The net upward and downward mass fluxes are made up of three components: their area fraction $\sigma$, the amplitude of the perturbation mass flux $m^{\prime}$, and the amplitude of the MSE perturbation $h_{u, d}-h_{2}$, where $h_{u, d}$ is the mean MSE of the upward and downward mass fluxes determined by the isentropic streamfunction, and $h_{2}$ is the MSE associated with the second model level, used to identify our parcel MSE, as shown in the following equation:

$$
w^{\prime} h^{\prime}=\sigma_{u} m_{u}^{\prime}\left(h_{u}-h_{2}\right)+\sigma_{d} m_{d}^{\prime}\left(h_{d}-h_{2}\right) .
$$

The subscripts $u$ and $d$ represent the areas of net positive and negative mass flux, respectively. Figure 9a

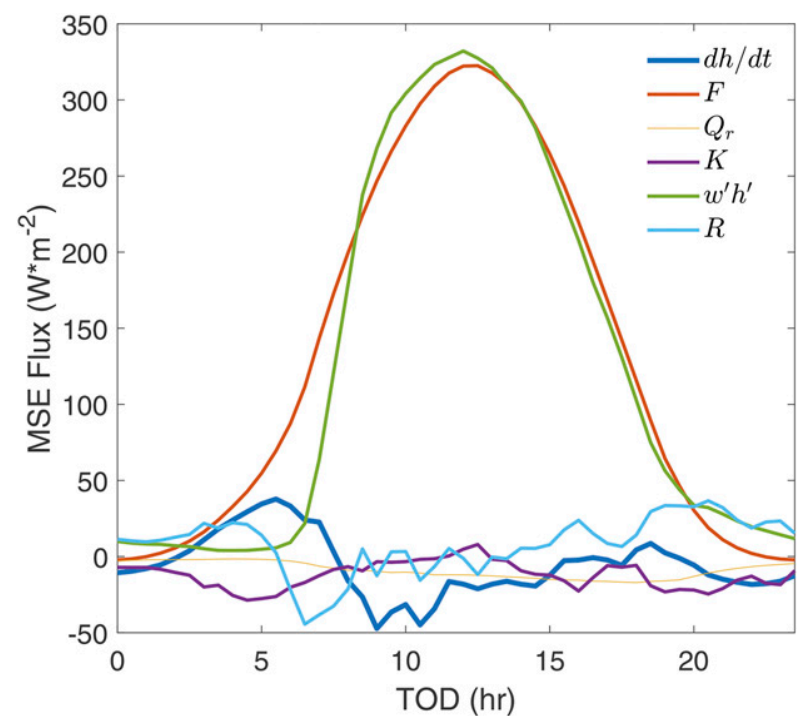

FIG. 8. Boundary layer MSE budget, with terms defined as in Eq. (8). All terms are composited into a diurnal cycle using 25 model days.

illustrates the total contributions of areas with net negative and positive mass flux. We can see that the MSE flux associated with downward net mass flux is much larger than that associated with upward net mass flux, though both terms are significant. At noon, net negative mass flux is contributing $79 \%$, while net positive mass flux contributes $21 \%$ to the total MSE eddy flux.

Net downward mass flux contributes the most to $w^{\prime} h^{\prime}$ due to the large difference in area fraction (Fig. 9b) and much larger perturbation MSE associated with net downward flow. This is shown in Fig. 9d, where the MSE anomalies relative to the second model level MSE are shown. Also shown are the critical MSE where the partitioning of net upward and downward mass flux occurs (green), and the MSE of the level directly above the LCL (magenta), which we will use to identify a potential contribution from entrainment to the net downward mass flux. Figure 9c shows that updrafts have a greater mass flux perturbation, even if the total contribution to the eddy flux is smaller.

Previous work has also attempted to distinguish contributions to BLQE in terms of updrafts, downdrafts, and entrainment (Raymond 1995; Raymond et al. 2015; Thayer-Calder and Randall 2015; Torri and Kuang 2016). Raymond (1995) and Raymond et al. (2015) mainly develop the theoretical framework for BLQE, while using knowledge about the atmosphere to infer which of the above three terms would be most relevant. Previous modeling studies separated between the three terms by using characteristics such as specific vertical velocities to partition (Thayer-Calder and Randall 2015), 

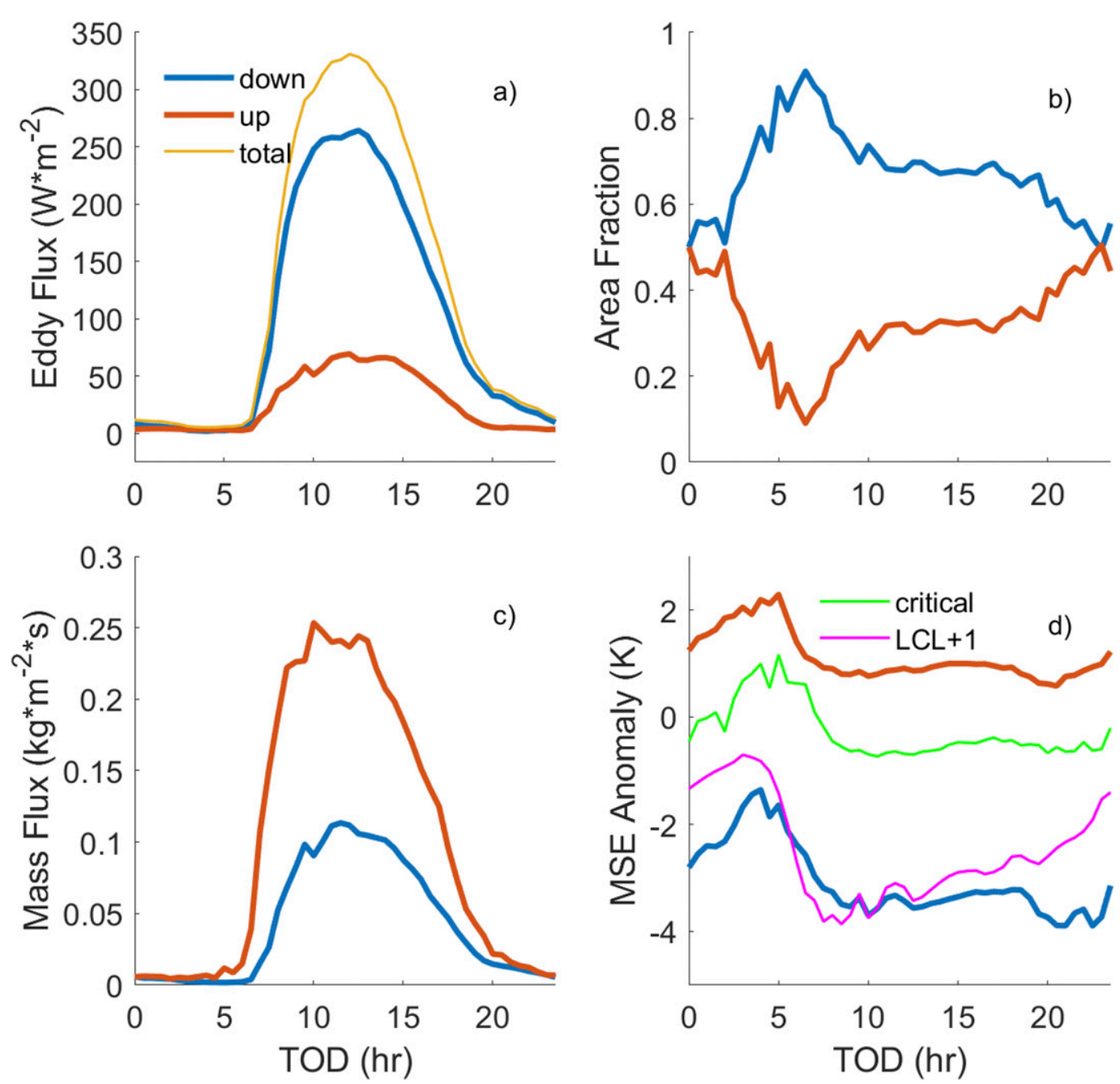

FIG. 9. Comparison of various terms associated with the eddy covariance of moist static energy $\left(w^{\prime} h^{\prime}\right)$ from the MSE budget in Eq. (10). Terms are separated by areas of net negative (blue line) and net positive (red line) mass flux and composited into a single diurnal cycle. (a) Total contribution to $w^{\prime} h^{\prime}$ by the net positive and negative mass fluxes. Total $w^{\prime} h^{\prime}$ is shown in orange. (b) Area fraction associated with the net positive and negative mass fluxes. (c) Amplitude of the mass flux associated with the two separated terms. Note that the net negative mass flux sign is flipped for comparison. (d) Various MSE anomaly time series. Blue and red lines represent the MSE anomaly of areas defined previously, green is the anomaly of the critical MSE for separating terms, and magenta is the MSE anomaly of the level directly above the LCL.

or used Lagrangian parcel tracking (Torri and Kuang 2016) to identify different categories of parcel buoyancy and saturation. Both studies using model data found that downdrafts were secondary compared to contributions from entrainment (Thayer-Calder and Randall 2015; Torri and Kuang 2016) and updrafts (Thayer-Calder and Randall 2015), though entrainment was always the largest contributor.

In some ways, our simulation agrees well with those considered above, with downward flow dominating to contribution to BLQE. However, unlike the above simulations, we do not explicitly categorize entrainment. We instead use the clear-sky dry static energy budget to quantify the largest possible entrainment contribution. Our downdraft versus entrainment contributions may differ greatly from those above, as we have no specific vertical velocity or buoyancy requirement for a downdraft. We use the dry static energy budget (dry static energy $s=c_{p} T+g z$ ) as in Raymond (1995) to identify the potential contribution from entrainment:

$$
\frac{d s}{d t}+u \cdot \nabla_{h} s+w \Gamma=Q_{r}
$$

where $u \cdot \nabla_{h} s$ is the horizontal advection of dry static energy, $w \Gamma$ is the vertical advection of dry static energy, 
as $\Gamma=d s / d z$, and $Q_{r}$ is the radiative cooling above the boundary layer. In Raymond (1995) by scale analysis, the only relevant terms were the vertical advection and radiative cooling. In our case, the $d s / d t$ term is still relevant; there is a diurnal cycle in dry static energy just above the boundary layer. We then use this clear sky $w$ as our entrainment velocity, and assume its MSE perturbation is the same as the level directly above the LCL, using the area fraction of all grid points with negative vertical velocity as its area fraction in order to calculate the maximum possible contribution from entrainment.

Figure 10 shows this potential contribution, as well as the total contribution from net negative mass flux (as in Fig. 9a). Prior to noon, a large portion of the downward net mass flux could be explained by entrainment. However, as the day continues, the potential contribution decreases. That entrainment makes its greatest contribution before noon makes sense physically, as we expect contributions from downdrafts to become greater as convection occurs. At noon, the maximum possible contribution of entrainment is about $50 \%$ of downward flow, or about $40 \%$ of the total contribution. One potential caveat of this result is that our entrainment contribution is sensitive to the vertical level chosen for the boundary layer top: higher levels can increase the downward MSE perturbation from the model level above, giving a greater entrainment contribution.

\section{CAPE in ERA-Interim}

Given the lack of difference in CAPE between our island and ocean simulations, we were interested in exploring how CAPE varies between land and ocean in the real world. In this case, we examine the total CAPE, as we know that free-tropospheric temperature gradients in the tropics are weak (Charney 1963). Using CAPE integrated to $500 \mathrm{hPa}$ does not change the conclusions of this analysis. Work by Riemann-Campe et al. (2009) showed that mean CAPE was not very different between land and ocean when using ERA-40 data. The use of sounding data has also been applied previously to look at differences between a few land points and ocean points, concluding that there were few differences (Williams and Renno 1993). Our goal with this analysis was to compare high percentiles of the global CAPE distribution, which is not necessarily going to follow the mean nor agree with a scattering of observation locations.

We calculated surface-based CAPE using 6-hourly ERA-Interim data from 2001 to 2008 in $\eta$ coordinates (so as not to include values below the surface, as in pressure coordinates) from $45^{\circ} \mathrm{N}$ to $45^{\circ} \mathrm{S}$. After calculating the CAPE, we then formed a probability density

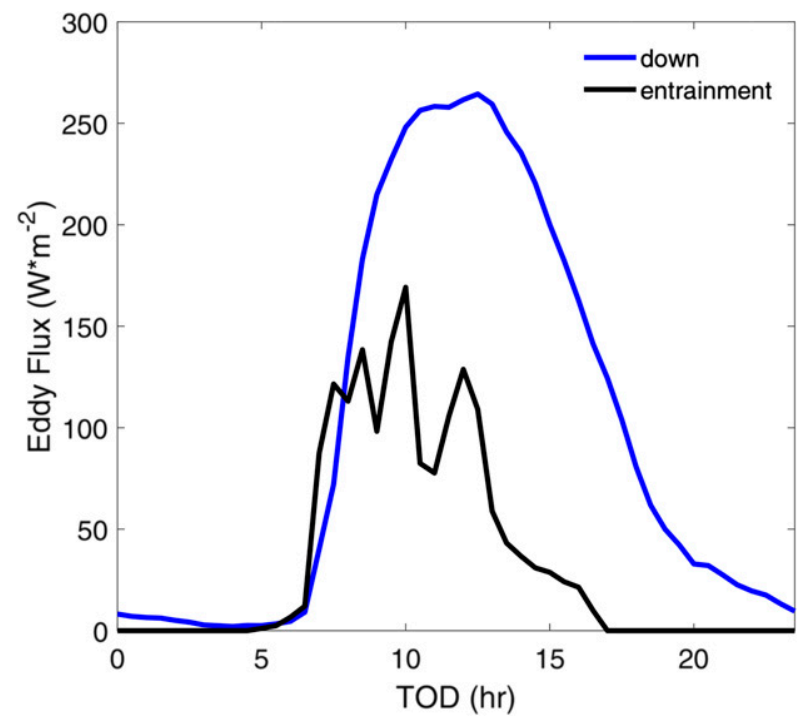

FIG. 10. Composite diurnal time series of MSE sink associated with net negative mass flux (blue) and maximum potential MSE sink contributed by entrainment as calculated by the clear sky dry static energy budget in Eq. (11) (black).

function for each grid point from these results. Our goal with this analysis was to capture the impact of the real world's diurnal cycle on CAPE, to see if high-percentile CAPEs are higher over land than over the ocean, following the initially proposed mechanism. This sort of reanalysis is not ideal, as one would prefer a greater temporal resolution to capture more characteristics of the diurnal cycle. However, four times each day should capture some characteristics and this reanalysis dataset is a good starting point.

Figure 11 shows each grid point's 75 th percentile of CAPE (Fig. 11a) and 99th percentile of CAPE (Fig. 11b). It is clear that even at the 99th percentile of CAPE over tropical landmasses, there are very few locations where CAPE is greater than that over the ocean. Only regions in northern India and parts of Southeast Asia show CAPE values greater than those in the west Pacific warm pool. This may be more evidence that a mechanism to prevent a boundary layer's moist static energy from becoming too large also exists in the real world over land, as in our simulations. Other explanations for previously observed mean CAPE similarity between land and ocean focused on fluctuations in the free-tropospheric temperature profile accounting for changes in surface temperature (Williams and Stanfill 2002). This was not the case in our simulation, with freetropospheric temperatures changing very little with time over our island, as shown in Fig. 7.

CAPE data from the 2014 and 2015 ARM GOAMAZON field campaign radiosonde profiles (Martin et al. 2016, 2017) showed results that did not 

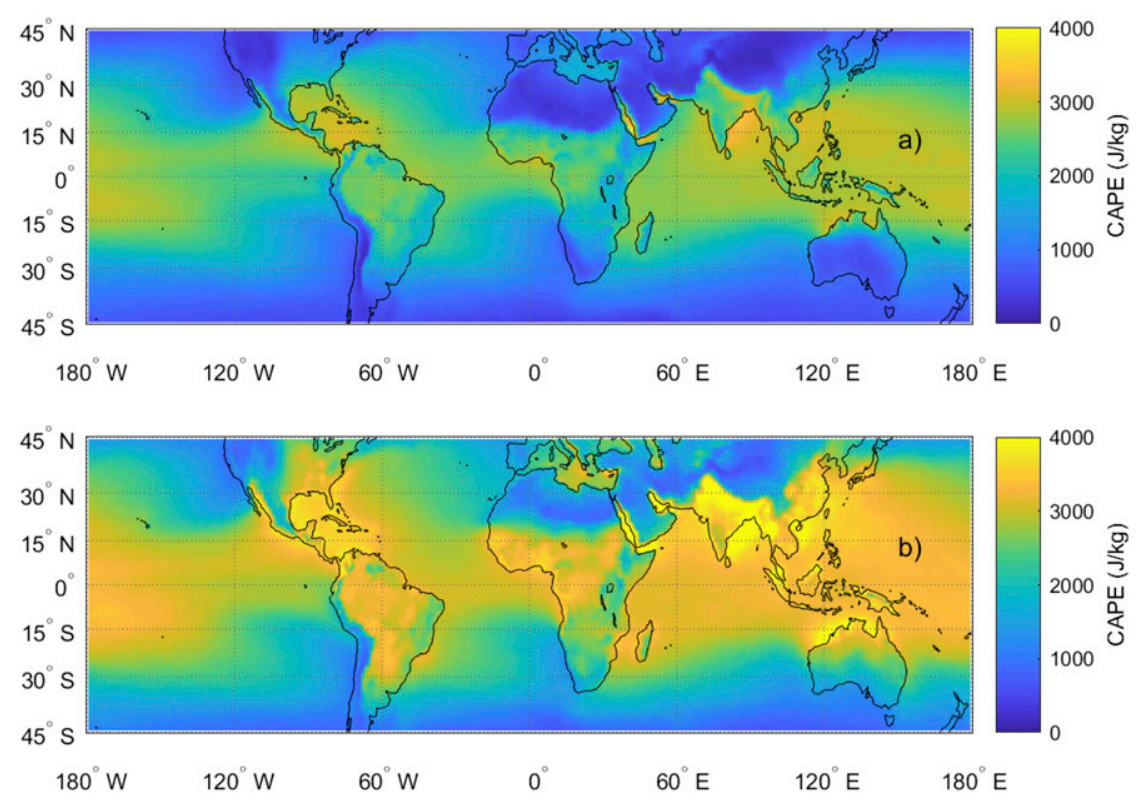

FIG. 11. (a) The 75th percentile of CAPE from ERA-Interim data, 2001-08, sampled four times daily. (b) The 99th percentile of CAPE from ERA-Interim over the same time period.

contradict the ERA-Interim result. Soundings were taken four times daily from the Manacapuru, Amazonas, Brazil, mobile sounding facility. The 75th and 99th percentiles of CAPE were 2275 and $3726 \mathrm{~J} \mathrm{~kg}^{-1}$, respectively. CAPE values from ERA-Interim gave a 75th percentile of approximately $2800 \mathrm{~J} \mathrm{~kg}^{-1}$ and a 99th percentile of approximately $3700 \mathrm{~J} \mathrm{~kg}^{-1}$. A more thorough analysis of surface observations from a variety of locations would be necessary to understand the extent of BLQE over land in the real world. This small analysis serves more as a sanity check for our reanalysis data.

\section{Discussion}

Understanding which physical mechanisms are most responsible for the regulation of the intensity of convection, and more specifically, the land-ocean contrast, is a scientific question that has still not been answered satisfactorily. We use the clear geographic contrast in lightning to gain intuition toward mechanisms that may influence the intensity of convection. The physical characteristics of land surfaces are then a natural direction when exploring mechanisms that may influence convective intensity.

We tested the impact of the diurnal cycle in surface heating on convective intensity. The tested diurnal cycle mechanism was proposed to work due to the interaction between a warmer land surface and a free troposphere influenced by oceanic convection. This would produce enhanced CAPE, leading to more intense convection over the island, even after using sampling to account for potentially enhanced precipitation.

In the real world, we were able to illustrate that the land-ocean contrast in lightning can be viewed independently from large-scale precipitation amount. It has been known previously that large-scale precipitation is not a good predictor for lightning (Petersen and Rutledge 1998; Petersen et al. 2005; Williams et al. 1992). However, our statement is a bit stronger: any physical mechanism that can explain the land-ocean contrast in convective intensity must still be able to do so after controlling for large-scale precipitation variations, including the diurnal cycle.

In our analysis of the global distribution of lightning, we wanted to gain intuition and physical insight into contrasts in convective intensity. If one considers warmrain precipitation events as a form of weak convection, then for our analysis it makes sense to keep those events when examining lightning after controlling for precipitation. However, there is little doubt that ice-phase metrics are a better predictor for lightning than total climatological precipitation (Petersen et al. 2005). Given that most warm-rain events occur over the ocean (Bréon et al. 2002), it seems likely that the same physical mechanisms responsible for enhanced ice and lightning over land are also responsible for fewer warm-rain events over land. Presumably, identifying the main mechanism for the land-ocean contrast in lightning would give us more insight into forcings that influence warm and mixed-phase precipitation processes. 
It would also be worthwhile to perform a sampling analysis using a variable other than climatological precipitation. Differences in precipitation efficiency between land and ocean may mean that surface rainfall over land differs for the same free-tropospheric rainfall value between land and ocean. It is not completely clear what value to choose, as many other variables have their own biases as well.

In our simulations, we can dismiss the diurnal cycle in surface heating as being responsible for a land-ocean contrast in convective intensity. After the application both Poisson sampling (for instantaneous data) and stratified sampling (for time-averaged data) to control large-scale precipitation, convective intensities were not enhanced over the island.

Due to the increased temporal coherence of island precipitation, time averaging still showed stronger updrafts over the island after Poisson sampling. This result was an artifact of the time averaging and not physically representative of the actual convection. This is worth consideration for those who examine contrasting areas where temporal distributions of precipitation or other variables differ: using temporal averaging when examining data can provide a result that does not exist when examining instantaneous output.

The diurnal cycle mechanism was suggested to work due to the interaction between an anomalously warm land surface and a free-tropospheric temperature profile influenced by oceanic convection with a surface temperature cooler than the land surface temperature. This would produce enhanced CAPE, leading to stronger convection over land, even when accounting for precipitation by sampling. However, in our simulations, the island area had similar CAPE to the ocean portion of the domain at times relevant to convection. An area of further examination may be into even more local CAPE variations: at any given time, we are still representing a geographic-mean CAPE over our island or ocean. If we had found notable convective strength differences with the same CAPE value shown in Fig. 6, this would be a natural place to explore. As it stands, this geographicmean CAPE result appears to agree with the lack of contrast in our updraft velocities.

A boundary layer MSE budget showed that our simulation's boundary layer could be described as being in a state of quasi equilibrium. This balance was mainly associated with the eddy flux of MSE at the top of the boundary layer, and occurred much more rapidly than had been previously described in Raymond (1995) and Raymond et al. (2015). Though not directly discussed, results from Thayer-Calder and Randall (2015) and Torri and Kuang (2016) also appear to also experience rapid BLQE, as the eddy flux and surface heat flux also appear to be collocated in time. However, their surface forcing was oceanic in nature, and thus somewhat more difficult to distinguish timing-wise.

We identified the individual contributions to BLQE in our simulations as being mainly from downdrafts and entrainment, with updrafts contributing a smaller portion. That updrafts contribute the least to BLQE matches other simulations (Thayer-Calder and Randall 2015; Torri and Kuang 2016). Our diagnosis of entrainment relied on the dry static energy budget rather than a specific environmental characteristic. This resulted in our maximum entrainment contribution being less than convective downdrafts, in agreement with Raymond (1995) and Raymond et al. (2015), which both used the dry static energy budget as well. It may be that many of our convective downdrafts are transient in that their vertical velocity or buoyancy perturbation are fairly small, and may have been classified as entrainment in Thayer-Calder and Randall (2015) or Torri and Kuang (2016).

One could also test the impact of the diurnal cycle in surface heating using a true WTG (or other parameterization of vertical motion) simulation setup (as in Raymond and Zeng 2005; Wang and Sobel 2011), where large-scale vertical motion over land is parameterized and used to advect a background water vapor profile that comes from a previously run ocean RCE simulation. This approach does have weaknesses as well: because the impact of the ocean is predefined, the land simulation cannot affect convection over the ocean, meaning that the true equilibrium thermodynamic environment is never reached. We do not expect a WTG simulation would change the qualitative results seen here, though it would be interesting to more systematically compare WTG results to this kind of island simulation. WTG would provide a framework for more thoroughly exploring the parameter space.

A natural question about our simulations is whether or not they are simply missing a real-world process that is integral to how the mechanism we are testing acts in the real world. When thinking about ideas like boundary layer quasi equilibrium, processes like boundary layers entraining air and downdrafts forming are relevant. Model resolution could be a factor limiting the realism of the simulation (Stevens et al. 1999; Cheng et al. 2010). Ideally, one would run these simulations at a much higher resolution to test the extent to which results converge with resolution. This would be worthwhile to do, but is beyond the scope of the current work. We have tested 500-m-resolution simulations and they behave qualitatively similar to what is shown in the rest of this paper. If it did turn out that the extent to which BLQE holds in simulations like ours varies with model 
resolution below $1 \mathrm{~km}$, this would be a notable limitation on CPM simulations in general for simulating processes like the diurnal cycle. This is worth further exploration and documentation if it is the case, as CPMs are widely used at $1-\mathrm{km}$ or coarser resolution for weather prediction.

Another possible issue with our simulations is that convection may be happening too easily over our island. As resolutions become coarser, CPMs can produce larger clouds, increased cloud fraction, and increased precipitation near the top of the boundary layer (Cheng et al. 2010). This is due to coarser-resolution simulations (including 1-km horizontal resolution) incorrectly partitioning kinetic energy between subgrid and resolved scales (Stevens et al. 1999; Cheng et al. 2010). Overestimation of cloud fraction and increased precipitation could lead to a greater quantity of convective downdrafts, creating the BLQE conditions we see in our simulation. A solution to the potential issue would be a higher simulation resolution. While 500-m-resolution simulations looked qualitatively similar to our current case, perhaps horizontal resolutions somewhere between 50 and $100 \mathrm{~m}$ are necessary to resolve appropriate turbulence, entrainment, and convective downdrafts (Bryan et al. 2003; Cheng et al. 2010).

Presuming resolution is not an issue in our case, another possible more realistic variation on our simulation would be to include a landlike surface Bowen ratio in addition to the diurnal cycle, which would give a more realistic distribution of surface fluxes. However, there is not a clear mechanism by which this would change the results. Altering the surface Bowen ratio provides its own issues related to precipitation and free-tropospheric temperature profiles (Hansen and Back 2015). This combination of issues might not be solvable through sampling techniques.

One could run this style of simulation with a simple land surface model as well, but we do not expect that would change our main conclusions. Understanding what is happening in such simulations would be more challenging once cloud shading by convection became involved. Land surface models may also have multiple landlike characteristics that are potentially relevant for convective intensity regulation. Examples are the surface Bowen ratio, the diurnal cycle in surface heating, and enhanced surface roughness. It becomes more challenging to distinguish the contributions between individual mechanisms when they are all included in a single simulation.

Some evidence for BLQE over land was also found in ERA-Interim data. We found that even at very high percentiles, CAPE over land is not higher than over the ocean, contrary to what our tested mechanism would predict. There are challenges with using reanalysis for examining the impact of the diurnal cycle on CAPE. GCMs have significant challenges representing the diurnal cycle of precipitation (e.g., Yang and Slingo 2001), which would affect the global distribution of CAPE at any percentile. A more systematic analysis with real observations would be necessary to determine what, role BLQE has in regulating CAPE over land. Also worth considering is that neither Fig. 10a nor Fig. 10b tells us which value of CAPE is actually responsible for producing convection. If different percentiles are associated with different regions of the planet, it is entirely plausible that CAPE is still responsible for convective intensity differences, even if any individual percentile of CAPE does not differ between regions. This also brings up the value of metrics that predict the probability of convection occurring rather than its strength: determining the relevant CAPE that a storm experiences is a challenging task, so a metric that tells us whether a storm will occur could help identify the potential CAPE the storm experiences.

Acting under the assumption that neither mean nor high-percentile CAPE differences can explain the landocean contrast in convective intensity, we must look for other mechanisms. Aerosols immediately become a much more likely mechanism for the contrast in lightning activity (Thornton et al. 2017; Fan et al. 2018), potentially in conjunction with a thermodynamic mechanism like in Stolz et al. (2015, 2017). One challenge of an aerosol hypothesis is that it may not effectively explain lightning contrasts that occur over small $\left(<1000 \mathrm{~km}^{2}\right)$ islands (Williams and Stanfill 2002). Bang and Zipser (2019) found that convective organization was more important than CAPE or other environmental parameters in determining lightning over the oceans. It would be worthwhile to perform similar analyses over land as well, to clarify which storms are successful at producing lightning. Perhaps some sort of forcing that drives the organization and aggregation of convection will be relevant in the land-ocean contrast.

A possible mechanism for aerosols to influence the land-ocean contrast is through controls on the entrainment and detrainment levels of convection. Higher aerosol loading may influence convective detrainment in such a way that saturation deficit of the free-tropospheric environment increases, leading to more CAPE and more intense convection (Singh and O'Gorman 2013, 2014; T. Abbott and T. Cronin 2019, personal communication). This extra buoyancy is determined as a parameter of the convection itself rather than an environmental variable, and thus we would not expect traditional parcel model-based CAPE calculations to capture the enhanced buoyancy of these storms. 
A way to examine the feasibility of this mechanism would be to examine the correlation between aerosol maps and maps of lightning adjusted via stratified sampling to clarify whether aerosols variations do in fact correlate with the sampled lightning maps. Additionally, while total aerosols may not explain a lightning contrast (Stolz et al. 2015), perhaps a certain aerosol size distribution like the ultrafine aerosols in Fan et al. (2018) may be worth more examination. This would be an interesting future direction to pursue.

\section{Conclusions}

We have used a combination of TRMM satellite data, CPM simulations, and ERA-Interim data to motivate and examine the impact that the diurnal cycle in surface heating plays on the intensity of convection, as measured by high-percentile updraft velocities. We describe our main conclusions here:

1) Maps of lightning, lightning divided by climatological precipitation, as well as lightning controlled by either Poisson or stratified sampling show a clear landocean contrast. Controlling the large-scale precipitation PDF with stratified sampling, we were able to decrease sampled lightning flash rates over land, but not enough to remove the land-ocean contrast, indicating that the precipitation distribution plays some role in influencing the land-ocean contrast in lightning, but not a dominant one.

2) In our model simulations, the diurnal cycle in surface temperature's influence on CAPE does not explain a land-ocean contrast in convective intensity. Impacts via differences in the precipitation distribution associated with the diurnal cycle did influence lightning, but not enough to explain the contrast. The diurnal cycle was predicted to increase CAPE over land through interaction with a cooler, oceanic freetropospheric temperature profile, resulting in greater updraft velocities over land. CPM simulations that featured an "island" with a 10-K diurnal cycle in surface temperature, and an "ocean" with a constant surface temperature showed mild high-intensity updraft velocity and precipitation enhancement over the island. After the application of statistical sampling, no significant convective intensity enhancement was found.

3) Rapid boundary layer quasi equilibrium occurring over our island prevented boundary layer MSE from increasing during times of surface warming, which in turn prevented CAPE from increasing. Using a MSE budget analysis of our island's boundary layer, we found that the BLQE balance was occurring mainly between surface fluxes and the eddy flux of MSE at the top of the boundary layer. A further analysis of this eddy flux allowed us to partition its contributions into convective updrafts, convective downdrafts, and entrainment. It was found that convective downdrafts contributed the most to the eddy flux, followed by entrainment. A much smaller contribution was made by convective updrafts.

4) Evidence for BLQE over land was also found in our examination of reanalysis data. Geographic distributions of individual CAPE percentiles from ERA-Interim data broadly did not match the initial prediction of the diurnal cycle mechanism: the mechanism predicted land having greater CAPE values than ocean at high percentiles, even if mean values of CAPE would not show a geographic contrast. Instead, geographic distributions of high CAPE percentile have their own unique distributions that do not clearly distinguish land and sea. This lack of a land-ocean contrast in high CAPE percentiles gives some evidence that BLQE may play a role in regulating CAPE over land in the real world as well.

Acknowledgments. This work was supported by NSF Grant 1549512, University of Wisconsin-Madison's Advanced Opportunity Fellowship, and a teaching assistantship in the Department of Statistics. We thank Tim Cronin, Tristan Abbott, Earle Williams, Adam Sobel, and two anonymous reviewers for their very helpful comments and suggestions. The authors also wish to thank Kerry Emanuel and David Raymond in their support of us working on this topic.

\section{REFERENCES}

Bang, S. D., and E. Zipser, 2019: Tropical oceanic thunderstorms near Kwajalein and the roles of evolution, organization, and forcing in their electrification. J. Geophys. Res. Atmos., 124, 544-562, https://doi.org/10.1029/2018JD029320.

Barthe, C., W. Deierling, and M. C. Barth, 2010: Estimation of total lightning from various storm parameters: A cloud-resolving model study. J. Geophys. Res., 115, D24202, https://doi.org/ 10.1029/2010JD014405.

Black, R. A., 1990: Radar reflectivity-ice water content relationships for use above the melting level in hurricanes. J. Appl. Meteor., 29, 955-961, https://doi.org/10.1175/1520-0450(1990) $029<0955$ :RRIWCR $>2.0$. CO; 2 .

Boccippio, D. J., 2002: Lightning scaling relations revisited. J. Atmos. Sci., 59, 1086-1104, https://doi.org/10.1175/1520-0469(2002) 059<1086:LSRR > 2.0.CO;2.

Bréon, F.-M., D. Tanré, and S. Generoso, 2002: Aerosol effect on cloud droplet size monitored from satellite. Science, $\mathbf{2 9 5}$, 834-838, https://doi.org/10.1126/science.1066434.

Bretherton, C. S., and P. K. Smolarkiewicz, 1989: Gravity waves, compensating subsidence and detrainment around cumulus clouds. J. Atmos. Sci., 46, 740-759, https://doi.org/10.1175/ 1520-0469(1989)046<0740:GWCSAD>2.0.CO;2. 
Bryan, G. H., J. C. Wyngaard, and J. M. Fritsch, 2003: Resolution requirements for the simulation of deep moist convection. Mon. Wea. Rev., 131, 2394-2416, https://doi.org/10.1175/ 1520-0493(2003)131<2394:RRFTSO > 2.0.CO;2.

Cecil, D. J., D. E. Buechler, and R. J. Blakeslee, 2014: Gridded lightning climatology from TRMM-LIS and OTD: Dataset description. Atmos. Res., 135-136, 404-414, https://doi.org/ 10.1016/j.atmosres.2012.06.028.

Charney, J. G., 1963: A note on large-scale motions in the tropics. J. Atmos. Sci., 20, 607-609, https://doi.org/10.1175/ 1520-0469(1963)020<0607:ANOLSM > 2.0.CO;2.

Cheng, A., K.-M. Xu, and B. Stevens, 2010: Effects of resolution on the simulation of boundary-layer clouds and the partition of kinetic energy to subgrid scales. J. Adv. Model. Earth Syst., 2 (1), https://doi.org/10.3894/JAMES.2010.2.3.

Chiang, J. C. H., and A. H. Sobel, 2002: Tropical tropospheric temperature variations caused by ENSO and their influence on the remote tropical climate. J. Climate, 15, 2616-2631, https://doi.org/ 10.1175/1520-0442(2002)015<2616:TTTVCB > 2.0.CO;2.

Cintineo, J. L., and Coauthors, 2018: The NOAA/CIMSS ProbSevere model: Incorporation of total lightning and validation. Wea. Forecasting, 33, 331-345, https://doi.org/10.1175/ WAF-D-17-0099.1.

Cronin, T. W., K. A. Emanuel, and P. Molnar, 2015: Island precipitation enhancement and the diurnal cycle in radiativeconvective equilibrium. Quart. J. Roy. Meteor. Soc., 141, 1017-1034, https://doi.org/10.1002/qj.2443.

Deierling, W., W. A. Petersen, J. Latham, S. Ellis, and H. J. Christian, 2008: The relationship between lightning activity and ice fluxes in thunderstorms. J. Geophys. Res., 113, D15210, https://doi.org/ 10.1029/2007JD009700.

Emanuel, K. A., 1995: The behavior of a simple hurricane model using a convective scheme based on subcloud-layer entropy equilibrium. J. Atmos. Sci., 52, 3960-3968, https://doi.org/ 10.1175/1520-0469(1995)052<3960:TBOASH >2.0.CO;2.

Fan, J., and Coauthors, 2018: Substantial convection and precipitation enhancements by ultrafine aerosol particles. Science, 359, 411-418, https://doi.org/10.1126/science.aan8461.

Finney, D. L., R. M. Doherty, O. Wild, H. Huntrieser, H. C. Pumphrey, and A. M. Blyth, 2014: Using cloud ice flux to parametrise large-scale lightning. Atmos. Chem. Phys., 14, 12 665-12 682, https://doi.org/10.5194/acp-14-12665-2014.

Hansen, Z. R., and L. E. Back, 2015: Higher surface Bowen ratios ineffective at increasing updraft intensity. Geophys. Res. Lett., 42, 10 503-10 511, https://doi.org/10.1002/2015GL066878.

Iacono, M. J., E. J. Mlawer, S. A. Clough, and J.-J. Morcrette, 2000: Impact of an improved longwave radiation model, RRTM, on the energy budget and thermodynamic properties of the NCAR Community Climate Model, CCM3. J. Geophys. Res., 105, 14 873-14 890, https://doi.org/10.1029/2000JD900091.

Imbens, G. W., and T. Lancaster, 1996: Efficient estimation and stratified sampling. J. Econom., 74, 289-318, https://doi.org/ 10.1016/0304-4076(95)01756-9.

Khairoutdinov, M. F., and D. A. Randall, 2003: Cloud resolving modeling of the ARM summer 1997 IOP: Model formulation, results, uncertainties, and sensitivities. J. Atmos. Sci., 60, 607-625, https://doi.org/10.1175/1520-0469(2003) 060<0607:CRMOTA $>2.0$. CO;2.

Kirstetter, P.-E., Y. Hong, J. J. Gourley, M. Schwaller, W. Petersen, and J. Zhang, 2013: Comparison of TRMM 2A25 products, version 6 and version 7, with NOAA/NSSL ground radar-based national mosaic QPE. J. Hydrometeor., 14, 661-669, https://doi.org/10.1175/JHM-D-12-030.1.
Lin, Y.-L., R. D. Farley, and H. D. Orville, 1983: Bulk parameterization of the snow field in a cloud model. J. Climate Appl. Meteor., 22, 1065-1092, https://doi.org/10.1175/1520-0450(1983) 022<1065:BPOTSF $>2.0$. CO;2.

Lucas, C., E. J. Zipser, and M. Lemone, 1994: Vertical velocity in oceanic convection off tropical Australia. J. Atmos. Sci., 51, 3183-3193, https://doi.org/10.1175/1520-0469(1994) 051<3183:VVIOCO $>2.0 . \mathrm{CO} ; 2$.

Mansell, E. R., and C. L. Ziegler, 2013: Aerosol effects on simulated storm electrification and precipitation in a two-moment bulk microphysics model. J. Atmos. Sci., 70, 2032-2050, https:// doi.org/10.1175/JAS-D-12-0264.1.

Martin, S. T., and Coauthors, 2016: Introduction: Observations and modeling of the Green Ocean Amazon (GoAmazon2014/5). Atmos. Chem. Phys., 16, 4785-4797, https://doi.org/10.5194/ acp-16-4785-2016.

— , and Coauthors, 2017: The Green Ocean Amazon experiment (GoAmazon2014/5) observes pollution affecting gases, aerosols, clouds, and rainfall over the rain forest. Bull. Amer. Meteor. Soc., 98, 981-997, https://doi.org/10.1175/BAMS-D-15-00221.1.

Muller, C. J., P. A. O'Gorman, and L. E. Back, 2011: Intensification of precipitation extremes with warming in a cloud-resolving model. J. Climate, 24, 2784-2800, https://doi.org/10.1175/ 2011JCLI3876.1.

Parodi, A., and K. Emanuel, 2009: A theory for buoyancy and velocity scales in deep moist convection. J. Atmos. Sci., 66, 3449-3463, https://doi.org/10.1175/2009JAS3103.1.

Pauluis, O. M., and A. Mrowiec, 2013: Isentropic analysis of convective motions. J. Atmos. Sci., 70, 3673-3688, https://doi.org/ 10.1175/JAS-D-12-0205.1.

Petersen, W. A., and S. A. Rutledge, 1998: On the relationship between cloud-to-ground lightning and convective rainfall. J. Geophys. Res., 103, 14 025-14040, https://doi.org/10.1029/ 97JD02064.

$\longrightarrow,-$, W. A. Petersen, and S. A. Rutledge, 2001: Regional variability in tropical convection: Observations from TRMM. J. Climate, 14, 3566-3586, https://doi.org/10.1175/1520-0442(2001) 014<3566:RVITCO >2.0.CO;2.

- H. J. Christian, and S. A. Rutledge, 2005: TRMM observations of the global relationship between ice water content and lightning. Geophys. Res. Lett., 32, L14819, https://doi.org/ 10.1029/2005GL023236.

Raymond, D. J., 1995: Regulation of moist convection over the west Pacific warm pool. J. Atmos. Sci., 52, 3945-3959, https:// doi.org/10.1175/1520-0469(1995)052<3945:ROMCOT> 2.0.CO;2.

— , and X. Zeng, 2005: Modelling tropical atmospheric convection in the context of the weak temperature gradient approximation. Quart. J. Roy. Meteor. Soc., 131, 1301-1320, https://doi.org/ 10.1256/qj.03.97.

_ C. S. Bretherton, and J. Molinari, 2006: Dynamics of the intertropical convergence zone of the east Pacific. J. Atmos. Sci., 63, 582-597, https://doi.org/10.1175/JAS3642.1.

— Z Ž. Fuchs, S. Gjorgjievska, and S. Sessions, 2015: Balanced dynamics and convection in the tropical troposphere. J. Adv. Model. Earth Syst., 7, 1093-1116, https://doi.org/10.1002/ 2015 MS000467.

Riemann-Campe, K., K. Fraedrich, and F. Lunkeit, 2009: Global climatology of convective available potential energy (CAPE) and convective inhibition (CIN) in ERA-40 reanalysis. Atmos. Res., 93, 534-545, https://doi.org/10.1016/j.atmosres.2008.09.037.

Robe, F. R., and K. Emanuel, 1996: Moist convective scaling: Some inferences from three-dimensional cloud ensemble simulations. 
J. Atmos. Sci., 53, 3265-3275, https://doi.org/10.1175/ 1520-0469(1996)053<3265:MCSSIF > 2.0.CO;2.

Robinson, F. J., S. C. Sherwood, and Y. Li, 2008: Resonant response of deep convection to surface hot spots. J. Atmos. Sci., 65, 276-286, https://doi.org/10.1175/2007JAS2398.1.

,-- D. Gerstle, C. Liu, and D. J. Kirshbaum, 2011: Exploring the land-ocean contrast in convective vigor using islands. J. Atmos. Sci., 68, 602-618, https://doi.org/10.1175/2010JAS3558.1.

Romps, D. M., A. B. Charn, R. H. Holzworth, W. E. Lawrence, J. Molinari, and D. Vollaro, 2018: CAPE times P explains lightning over land but not the land-ocean contrast. Geophys. Res. Lett., 45, 12 623-12 630, https://doi.org/10.1029/2018GL080267.

Särndal, C.-E., B. Swensson, and J. Wretman, 1992: Model Assisted Survey Sampling. Springer Series in Statistics, SpringerVerlag, 694 pp.

Simpson, J., C. Kummerow, W. K. Tao, and R. F. Adler, 1996: On the Tropical Rainfall Measuring Mission (TRMM). Meteor. Atmos. Phys., 60, 19-36, https://doi.org/10.1007/BF01029783.

Singh, M. S., and P. A. O'Gorman, 2013: Influence of entrainment on the thermal stratification in simulations of radiativeconvective equilibrium. Geophys. Res. Lett., 40, 4398-4403, https://doi.org/10.1002/grl.50796.

$\longrightarrow$, and —, 2014: Increases in moist-convective updraft velocities with warming in radiative-convective equilibrium. Quart. J. Roy. Meteor. Soc., 141, 2828-2838, https://doi.org/ 10.1002/qj.2567.

Sobel, A. H., and C. S. Bretherton, 2000: Modeling tropical precipitation in a single column. J. Climate, 13, 4378-4392, https://doi.org/10.1175/1520-0442(2000)013<4378:MTPIAS> 2.0.CO;2.

_ C. D. Burleyson, and S. E. Yuter, 2011: Rain on small tropical islands. J. Geophys. Res., 116, D08102, https://doi.org/10.1029/ 2010JD014695.

Stevens, B., C.-H. Moeng, and P. P. Sullivan, 1999: Large-eddy simulations of radiatively driven convection: Sensitivities to the representation of small scales. J. Atmos. Sci., 56, 3963-3984, https://doi.org/10.1175/1520-0469(1999)056<3963:LESORD> 2.0.CO;2.

Stolz, D. C., S. A. Rutledge, and J. R. Pierce, 2015: Simultaneous influences of thermodynamics and aerosols on deep convection and lightning in the tropics. J. Geophys. Res. Atmos., 120, 6207-6231, https://doi.org/10.1002/2014JD023033.

,,,--- , and S. C. van den Heever, 2017: A global lightning parameterization based on statistical relationships among environmental factors, aerosols, and convective clouds in the TRMM climatology. J. Geophys. Res. Atmos., 122, 7461-7492, https://doi.org/10.1002/2016JD026220.

Sullivan, S. C., D. Lee, L. Oreopoulos, and A. Nenes, 2016: Role of updraft velocity in temporal variability of global cloud hydrometeor number. Proc. Natl. Acad. Sci. USA, 113, 5791-5796, https://doi.org/10.1073/pnas.1514039113.

Takahashi, T., 1978: Riming electrification as a charge generation mechanism in thunderstorms. J. Atmos. Sci., 35, 1536-1548, https://doi.org/10.1175/1520-0469(1978)035<1536:REAACG > 2.0.CO;2.

Takayabu, Y. N., 2006: Rain-yield per flash calculated from TRMM PR and LIS data and its relationship to the contribution of tall convective rain. Geophys. Res. Lett., 33, L18705, https://doi.org/10.1029/2006GL027531.

Thayer-Calder, K., and D. Randall, 2015: A numerical investigation of boundary layer quasi-equilibrium. Geophys. Res. Lett., 42, 550-556, https://doi.org/10.1002/2014GL062649.
Thornton, J. A., K. S. Virts, R. H. Holzworth, and T. P. Mitchell, 2017: Lightning enhancement over major oceanic shipping lanes. Geophys. Res. Lett., 44, 9102-9111, https://doi.org/ 10.1002/2017GL074982.

Torri, G., and Z. Kuang, 2016: A Lagrangian study of precipitationdriven downdrafts. J. Atmos. Sci., 73, 839-854, https://doi.org/ 10.1175/JAS-D-15-0222.1.

Varble, A., and Coauthors, 2014: Evaluation of cloud-resolving and limited area model intercomparison simulations using TWP-ICE observations: 1. Deep convective updraft properties. J. Geophys. Res. Atmos., 119, 13 891-13918, https:// doi.org/10.1002/2013JD021371.

Wang, S., and A. H. Sobel, 2011: Response of convection to relative sea surface temperature: Cloud-resolving simulations in two and three dimensions. J. Geophys. Res., 116, D11119, https:// doi.org/10.1029/2010JD015347.

_, and _ 2017: Factors controlling rain on small tropical islands: Diurnal cycle, large-scale wind speed, and topography. J. Atmos. Sci., 74, 3515-3532, https://doi.org/10.1175/ JAS-D-16-0344.1.

Williams, E. R., 1992: The Schumann resonance: A global tropical thermometer. Science, 256, 1184-1187, https://doi.org/10.1126/ science. 256.5060 .1184 .

- , and N. Renno, 1993: An analysis of the conditional instability of the tropical atmosphere. Mon. Wea. Rev., 121, 21-36, https:// doi.org/10.1175/1520-0493(1993)121<0021:AAOTCI > 2.0.CO;2.

— , and S. Stanfill, 2002: The physical origin of the land-ocean contrast in lightning activity. C. R. Phys., 3, 1277-1292, https:// doi.org/10.1016/S1631-0705(02)01407-X.

—_, S. G. Geotis, N. Renno, S. A. Rutledge, E. Rasmussen, and T. Rickenbach, 1992: A radar and electrical study of tropical "hot towers." J. Atmos. Sci., 49, 1386-1395, https://doi.org/10.1175/1520-0469(1992)049<1386:ARAESO> 2.0.CO;2.

_- and Coauthors, 2002: Contrasting convective regimes over the Amazon: Implications for cloud electrification. J. Geophys. Res., 107, 8082, https://doi.org/10.1029/ 2001JD000380.

- T. Chan, and D. J. Boccippio, 2004: Islands as miniature continents: Another look at the land-ocean lightning contrast. J. Geophys. Res., 109, D16206, https://doi.org/10.1029/ 2003JD003833.

, V. Mushtak, D. Rosenfeld, S. Goodman, and D. Boccippio, 2005: Thermodynamic conditions favorable to superlative thunderstorm updraft, mixed phase microphysics and lightning flash rate. Atmos. Res., 76, 288-306, https://doi.org/ 10.1016/j.atmosres.2004.11.009

Yang, G.-Y., and J. Slingo, 2001: The diurnal cycle in the tropics. Mon. Wea. Rev., 129, 784-801, https://doi.org/10.1175/1520-0493(2001) 129<0784:TDCITT>2.0.CO;2.

Zipser, E. J., 2003: Some views on "hot towers" after 50 years of tropical field programs and two years of TRMM data. Cloud Systems, Hurricanes, and the Tropical Rainfall Measuring Mission (TRMM) - A Tribute to Dr. Joanne Simpson, Meteor. Monogr., No. 29, Amer. Meteor. Soc., 49-58, https://doi.org/ 10.1175/0065-9401(2003)029<0049:CSVOHT>2.0.CO;2.

, and K. R. Lutz, 1994: The vertical profile of radar reflectivity of convective cells: A strong indicator of storm intensity and lightning probability? Mon. Wea. Rev., 122, 1751-1759, https://doi.org/10.1175/1520-0493(1994)122<1751:TVPORR> 2.0.CO;2. 